bioRxiv preprint doi: https://doi.org/10.1101/2021.08.02.454636; this version posted August 2, 2021. The copyright holder for this preprint (which was not certified by peer review) is the author/funder, who has granted bioRxiv a license to display the preprint in perpetuity. It is made available under aCC-BY-ND 4.0 International license.

\title{
Postnatal SETD1B is essential for learning and the regulation of neuronal plasticity genes.
}

2

Alexandra Michurina ${ }^{1 *}$, M Sadman Sakib $^{1 *}$, Cemil Kerimoglu ${ }^{1 * \$}$, Dennis Manfred Krüger ${ }^{1}$, Lalit Kaurani $^{1}$, Md Rezaul Islam ${ }^{1}$, Joshi Parth Devesh ${ }^{2}$, Sophie Schröder ${ }^{1}$, Tonatiuh Pena Centeno ${ }^{1}$, Jiayin Zhou $^{1}$, Ranjit Pradhan ${ }^{1}$, Julia Cha ${ }^{1}$, Xingbo Xu ${ }^{2}$, Gregor Eichele ${ }^{2}$, Elisabeth M. Zeisberg ${ }^{3,4,5}$ Andrea $\mathrm{Kranz}^{6}$, A. Francis Stewart ${ }^{6,7}$, Andre Fischer ${ }^{1,5,7,8, \$}$

${ }^{1}$ Department for Systems Medicine and Epigenetics, German Center for Neurodegenerative Diseases (DZNE), Von Siebold Str. 3a, 37075, Göttingen, Germany

${ }^{2}$ Department for Gene and Behavior, Max Planck Institute for Biophysical Chemistry, Am Fassberg 11, 37077, Göttingen, Germany

${ }^{3}$ Department of Cardiology and Pneumology, University Medical Center of Göttingen, Georg-August University, Germany, Robert Koch Str. 40, 37075 Göttingen, Germany

${ }^{4}$ German Centre for Cardiovascular Research (DZHK), Partner Site Göttingen, Germany

${ }^{5}$ Cluster of Excellence "Multiscale Bioimaging: from Molecular Machines to Networks of Excitable Cells" (MBExC), University of Göttingen, Germany

${ }^{6}$ Biotechnology Center, Center for Molecular and Cellular Bioengineering, Dresden University of Technology, Dresden 01307, Germany

${ }^{7}$ Max-Planck-Institute for Cell Biology and Genetics, Dresden, 01307, Germany

${ }^{8}$ Department of Psychiatry and Psychotherapy, University Medical Center Göttingen, Von Siebold Str 5, 37075 Göttingen, Germany

§Corresponding authors: cemil.kerimoglu@dzne.de; andre.fischer@dzne.de

* equal contribution

Short title: Postnatal Setd1 $b$ regulates cognition

\section{ABSTRACT}

Histone 3 lysine 4 methylation (H3K4me) is mediated by six different lysine methyltransferases. Amongst these enzymes SET domain containing 1b (SETD1B) has been linked to syndromic intellectual disability but its role in the postnatal brain has not been studied yet. Here we employ mice that lack Setdlb from excitatory neurons of the postnatal forebrain and combine neuron-specific ChIP-seq and RNA-seq approaches to elucidate its role in neuronal gene expression. We observe that $\underline{\text { SETD1B controls the expression of genes with a broad H3K4me3 peak at their promoters that }}$ represent neuronal enriched genes linked to learning and memory function. Comparative analysis to corresponding data from conditional $K m t 2 a$ and $K m t 2 b$ knockout mice suggests that this function is specific to SETD1B. Moreover, postnatal loss of Setdlb leads to severe learning impairment, suggesting that SETD1B-mediated regulation of H3K4me levels in postnatal neurons is critical for cognitive function.

Keywords: histone-methylation, learning \& memory, ChIP-seq, cognitive diseases 


\section{INTRODUCTION}

Adult-onset cognitive diseases, such as for example sporadic Alzheimer's disease (AD), depend on complex interactions of genetic and environmental risk factors that activate epigenetic processes (Fischer, 2014). In addition, mutations in genes that control epigenetic gene regulation are over-represented in neurodevelopmental diseases linked to cognitive dysfunction (Kleefstra et al, 2014) (Gabriele et al, 2018). Therefore, targeting the epigenome has emerged as a promising therapeutic avenue to treat neurodevelopmental and adult-onset cognitive diseases (Fischer, 2014; Nestler et al, 2015) (Larizza \& Finelli, 2019). To understand the regulation of epigenetic gene expression in in the context of cognitive function is thus of utmost importance. Increasing evidence hints to a especially important role histone 3 lysine 4 (H3K4me) methylation, a mark linked to active transcription. In mammals, H3K4 methylation is mediated by six different lysine methyltransferases (KMTs), namely KMT2A (M111), KMT2B (M112), KMT2C (M113), KMT2D (M114), SETD1A, and SETD1B that catalyze - with some specificity - mono-, di- and trimethylation (Shilatifard, 2012). Importantly, mutations in all of these enzymes are found in neurodevelopmental intellectual disability disorders and a substantial amount of work has focused on the role of these enzymes in cortical development (Gabriele et al., 2018). Neuronal H3K4me is also deregulated in adult-onset neurodegenerative diseases, such as Alzheimer's disease (AD) (Gjoneska et al, 2015). Moreover, exposure of mice to a learning task was shown to increase H3K4me levels in postnatal brain (Gupta et $a l, 2010)$. However, the role of the different H3K4 KMTs in the postnatal brain is not well understood yet. Thus, it is presently also unclear to what extent postnatal processes may contribute to the cognitive phenotypes observed in intellectual disability disorders that are linked to mutations in the different H3K4 KMTs. Such knowledge is important for the development of therapeutic approaches. Amongst the six H3K4 KMTs, SETD1B is the least studied enzyme. Virtually nothing is known about the function of SETD1B in postnatal brain, although mutations in the Setdlb gene have been linked to syndromic intellectual disability (Hiraide et al, 2018) (Labonne et al, 2016) (Roston et al, 2020). Therefore, to elucidate the role of Setdlb we generated mice that lack the gene from excitatory neurons of the postnatal brain and analyzed cognitive function and epigenetic gene expression in young adult mice. Our data reveal that Setdlb is essential for memory formation. Moreover, we provide evidence that Setd $1 b$ controls the expression of genes that are characterized by a broad H3K4 trimethylation peak around the transcription start site (TSS) and are intimately linked to neuronal function and learning behavior. A comparative analysis to corresponding data from conditional Kmt $2 a$ and $K m t 2 b$ knockout mice suggest a distinct role for $S e t d 1 b$ in the regulation of epigenetic gene expression linked to learning processes.

\section{RESULTS}

Loss of Setd1b in postnatal forebrain neurons impairs hippocampus-dependent memory formation. 
To study the role of Setdlb in the postnatal brain, we crossed mice in which exon 5 of the Setdlb gene is flanked by loxP sites to mice that express CRE-recombinase under control of the CamKII promoter (Minichiello et al, 1999). This approach ensures deletion of Setdlb from excitatory forebrain neurons of the postnatal brain (cKO mice). Quantitative PCR (qPCR) analysis confirmed decreased expression of Setdlb in the hippocampal Cornu Ammonis (CA) area, the dentate gyrus (DG) and the cortex when compared to corresponding control littermates that carry loxP sites but do not express CRE recombinase (control group). Expression in the cerebellum was not affected, confirming the specificity of the approach (Fig 1A). Residual expression of Setdlb in the forebrain regions is most likely due to the fact that deletion is restricted to excitatory neurons while other cell types are unaffected. In line with the qPCR data, SETD1B protein levels were reduced in the hippocampal CA region of Setdl $b$ cKO mice (Fig 1B). Setdlb cKO mice did not show any gross abnormalities in brain anatomy as evidenced by immunohistological analysis of DAPI staining, staining of marker proteins for neuronal integrity Neuronal $\mathrm{N}$ (NeuN), microtubule-associated protein 2 (MAP2) as well as ionized calcium-binding adapter molecule 1 (IBA1) as a marker for microglia and glial fibrillary acidic protein (GFAP) as a marker for astrocytes (Fig. 1C). Next, we subjected Setdlb cKO and control mice to behavior testing. Notably, it was previously shown that heterozygous mice expressing CRE under control of the CamKII promoter do not differ from wild type littermates (Kuczera et al, 2010) (Stilling et al, 2014)and we have confirmed this in the context of the present study also for behavior testing (Fig. EV1). There was no difference amongst groups in the open field test, suggesting that explorative behavior and basal anxiety is normal in Setdlb cKO mice (Fig 1D). Short term memory was assayed via the $\underline{\mathrm{Y} \text {-maze }}$ and was also similar amongst groups (Fig 1E). We also tested depressive-like behavior in the Porsolt forced swim test. No difference was observed amongst groups (Fig 1F). Next, we subjected mice to the Morris Water Maze test to study hippocampusdependent spatial memory. While control mice were able to learn the task as indicated by a reduced escape latency throughout the 10 days of training, Setd $1 b$ cKO mice were severely impaired (Fig 1G). We also performed a more sensitive analysis using a modified version of the MUST-C algorithm to measure the different spatial strategies that represent either hippocampus-dependent or independent abilities (Illouz et al, 2016) (Islam et al, 2021). Our results show that Setdlb cKO mice fail to adopt hippocampus-dependent search strategies such as "direct", "corrected" and "short-chaining" (Fig 1H). Consistently, the cumulative learning score calculated on the basis of these search strategies showed severe learning impairment in Setdlb cKO mice (Fig 1I). Since memory acquisition was severely impaired in Setdlb cKO mice, and we moreover observed a trend for reduced swim speed during a probe test that was performed after the end of the training procedure, memory recall could not be analyzed (Fig. EV2). In conclusion, our data show that deletion of Setd1b from excitatory neurons of the postnatal forebrain leads to severe impairment of hippocampus-dependent learning abilities.

\section{Setd1d controls H3K4 methylation peak width in hippocampal excitatory neurons}


bioRxiv preprint doi: https://doi.org/10.1101/2021.08.02.454636; this version posted August 2, 2021. The copyright holder for this preprint (which was not certified by peer review) is the author/funder, who has granted bioRxiv a license to display the preprint in perpetuity. It is made available under aCC-BY-ND 4.0 International license.

Although the Morris water maze test is used to specifically measure hippocampus-dependent

118 learning and memory, we cannot exclude that other brain regions contribute to the observed learning

119 impairment. Nevertheless, our data suggest that the hippocampus would be a suitable brain region to

120 study the molecular function of neuronal Setdlb in the postnatal brain. We reasoned that analyzing the

121 hippocampus would furthermore allow for an optimal comparison to previous studies that investigated

122 epigenetic gene expression from hippocampal neurons and tissue obtained from Kmt2a and Kmt2b

123 cKO mice, that were generated using the same CRE-driver line as in this study (Kerimoglu et al,

124 2013; Kerimoglu et al, 2017). To this end we isolated the hippocampal CA region from Setdlb cKO

125 and control mice and prepared nuclei to perform neuron-specific chromatin immunoprecipitation

126 (ChIP) (Fig 2A). Since SETD1B is a histone 3 lysine 4 (H3K4) methyltransferase we decided to

127 analyze tri-methylation ( $\mathrm{H} 3 \mathrm{~K} 4 \mathrm{me} 3)$ of histone 3 lysine 4 that is enriched at the transcription start site

128 (TSS) of active genes and is associated with euchromatin and active gene expression. H3K4

129 methylation is believed to be a stepwise process and recent data suggest that the different methylation

130 states (from mono- to tri-methylation) at the TSS of a gene form a gradient reflecting its specific

131 transcriptional state (Choudhury et al, 2019; Soares et al, 2017). Moreover, some specificity for

132 mono- di- or tri-methylation has been reported for the different H3K4 KMTs, although biochemical

133 analysis does not always correspond to the in vivo data (Bochyńska et al, 2018; Kerimoglu et al.,

134 2017) (Gabriele et al., 2018). Thus, we also analyzed mono-methylation of histone 3 at lysine 4

135 (H3K4me1). In addition, we analyzed histone 3 lysine 9 acetylation (H3K9ac), a euchromatin mark

136 that was shown to partially depend on H3K4 methylation (Kerimoglu et al., 2013). Finally, we also

137 performed ChIP-Seq for histone 3 lysine 27 acetylation (H3K27ac), another euchromatin mark that is

138 linked to active gene expression and marks promoter elements around the TSS but also enhancer

139 regions and has not been directly linked to H3K4me3 in brain tissue. In all ChIP-Seq experiments we

140 observed a clear separation between control and Setdlb cKO samples as evidenced by principal

141 component analysis (Fig EV3).

142 Loss of Setd1b leads to a substantial decrease in neuronal H3K4me3 (adjusted $p$-value $<0.05$

$143 \&$ fold change $<-1.5)$ across the genome while the majority of significant changes are localized to

144 regions in proximity to TSS (Fig 2B, C; Supplementary Table 1). Similar changes were observed

145 for neuronal $\mathrm{H} 3 \mathrm{~K} 9 \mathrm{ac}$ and $\mathrm{H} 3 \mathrm{~K} 27 \mathrm{ac}$, although fewer regions were affected when compared to

146 H3K4me3 (Fig. EV4; Supplementary Tables 2 and 3). The changes in H3K9ac showed a

147 substantial convergence with altered H3K4me3 (Fig EV4C). Thus, almost all TSS regions (+/- 2kb)

148 exhibiting decreased H3K9ac were also marked by decreased H3K4me3, while the TSS regions

149 showing decreased H3K27ac only partially overlapped with those with decreased H3K4me3 (Fig

150 EV4C). These data support previous findings, showing that $\mathrm{H} 3 \mathrm{~K} 4 \mathrm{me} 3$ is functionally linked to

151 H3K9ac (Kerimoglu et al., 2013) and suggest that the observed changes in H3K27ac might also

152 reflect secondary effects. 
153 We also observed significantly altered H3K4me1 levels (adjusted $p$-value $<0.05 \& \mid$ fold change $\mid<$

$154 \quad 1.5$ ) in neurons of Setdlb cKO mice (Fig 2B; Supplementary Table 4). These changes were also

155 almost exclusively detected in vicinity to the TSS (Fig 2B) but in contrast to the other investigated

156 histone modifications, many of the significantly altered genomic regions exhibited increased

157 H3K4me1 levels in Setdlb cKO mice (Fig. 2B, C), suggesting that Setdlb may mainly promotes tri-

158 methylation of $\mathrm{H} 3 \mathrm{~K} 4$ in neurons. To further interpret these observations, we analyzed the distribution

159 of altered H3K4 methylation across the TSS region including up- and downstream regions up to $5 \mathrm{~kb}$.

160 Interestingly, decreased $\mathrm{H} 3 \mathrm{~K} 4 \mathrm{me} 3$ in cKO manifested itself exclusively downstream of the TSS,

161 indicating that loss of Sedtlb may affect peak width (Fig 2D). We decided to further explore this

162 observation and detected two distinct patterns of altered H3K4me. Namely, there was a difference

163 between the genes that exhibit decreased H3K4me3 and at the same time increased H3K4me1 (Fig.

164 2E) and those that show concomitantly decreased H3K4 tri- and mono-methylation around the TSS

165 (Fig 2F). The change in H3K4me3 was most significant in genes with decreased H3K4me3 and

166 increased H3K4me1 and was characterized by a substantially reduced H3K4me3 peak width (Fig 2E),

167 when compared to genes with milder yet significantly decreased H3K4me3 and H3K4me1 (Fig 2F).

168 Findings from other cell types suggest a gradient of H3K4 methylation states in which the proximity

169 of the mark to the TSS is correlated to the level of gene expression. Thus, genes with broader

170 H3K4me3 peaks at the TSS exhibit the highest and most consistent expression levels and represent

171 genes of particular importance for cellular identity and function (Benayoun et al, 2015) (Soares et al.,

172 2017). Our data revealed that the genes which are characterized by decreased H3K4me 3 and

173 increased H3K4me1 in Setd1b cKO mice, exhibit significantly broader H3K4me3 peaks under basal

174 conditions, when compared to genes characterized by decreased H3K4me3 but either decreased or

175 unchanged H3K4me1 levels (Fig 2G; Supplementary Table 5). Interestingly, these genes were also

176 expressed at significantly higher levels under baseline conditions (Fig $2 \mathbf{H}$; Supplementary Table 6).

177 Gene-ontology (GO) analysis revealed that the genes with decreased H3K4me3 and increased

$178 \mathrm{H} 3 \mathrm{~K} 4 \mathrm{me} 1$ and thus having the broadest H3K4me3 peaks under basal conditions, represent pathways

179 intimately linked to the function of excitatory hippocampal neurons (Fig 2I; Supplementary Table

180 7). Most importantly, this was not the case for the genes of the other two categories (Fig 2I). Finally,

181 through motif enrichment analysis we observed that the TSS regions with decreased H3K4me3 and

182 increased H3K4me1 show a significant enrichment for RE1 Silencing Transcription Factor (REST)

183 consensus binding site (Supplementary Table 8), which is in line with our GO-term analysis since

184 the REST complex has previously been shown to repress genes specifically important for synaptic

185 plasticity and specific to neuronal function both during development and aging by recruiting an

186 enzymatic machinery that mediates heterochromatin formation and thus acts as counterplayer the

$187 \quad$ H3K4 methyltransferases such as SETD1B (Hwang \& Zukin, 2018). 
bioRxiv preprint doi: https://doi.org/10.1101/2021.08.02.454636; this version posted August 2, 2021. The copyright holder for this preprint (which was not certified by peer review) is the author/funder, who has granted bioRxiv a license to display the preprint in perpetuity. It is made available under aCC-BY-ND 4.0 International license.

In summary, our data show that loss of Setd1b from hippocampal excitatory neurons leads to distinct changes in neuronal histone methylation and point to a specific role of SETD1B in the H3K4 tri-methylation and the expression of genes essential for hippocampal excitatory neuronal function.

\section{Setdlb controls the levels of highly expressed hippocampal excitatory neuronal genes characterized} by a broad H3K4me3 peak at the TSS

To test the impact of SETD1B on gene expression directly, we analyzed RNA-sequencing data obtained from neuronal nuclei of the same hippocampi used to generate ChIP-seq data. This was possible since we had employed a modified fixation protocol that allowed us to perform neuronspecific ChIP-seq and RNA-seq from the same samples (See Fig 2A, Fig EV5). In line with the established role of $\mathrm{H} 3 \mathrm{~K} 4 \mathrm{me} 3$ in active gene expression, we mainly detected downregulated genes when comparing control to Setdlb cKO mice (adjusted $p$-value $<0.1 \&$ fold change $\mid<1.2$ ) (Fig 3A, Fig EV6; Supplementary Table 9). The comparatively few up-regulated genes mainly exhibited low expression at baseline (RPKM down-regulated genes $=18.77+/-1.45$ vs. $\underline{\text { RPKM }}$ up-regulated genes $=$ $3.08+/-0.26$; $\underline{\text { Student's t-test } p \text {-value }}<0.0001)$. Further analysis revealed that the TSS region of genes down-regulated in Setdlb cKO mice is characterized by significantly reduced $\mathrm{H} 3 \mathrm{~K} 4 \mathrm{me} 3$ peak width and increased H3K4me1 (Fig 3B, 3D), which was not the case for an equally sized random sample of unaffected genes (Fig 3C). H3K9ac and H3K27ac levels were also reduced at the TSS of the down-regulated genes (Fig EV7). This observation was specific to the genes down-regulated in Setd $1 b$ cKO mice, since random sets of genes that were not dysregulated in Setdlb cKO mice show

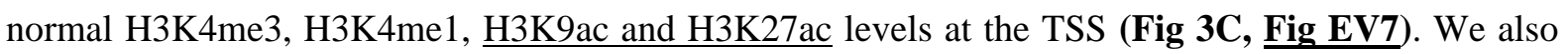
observed that the genes downregulated as a result of Setdlb deletion were characterized by a significantly broader H3K4me3 peak around TSS and higher expression under basal conditions, when compared to unaffected genes (Fig 3E; Supplementary Tables 10 and 11).

GO analysis revealed that the genes down-regulated in Setdlb cKO mice are linked to synaptic plasticity and learning related processes such as for example ERK1/2 signaling, extracellular matrix organization or neuropeptide signaling pathways(Borbély et al, 2013; Sweatt, 2001) (Tsilibary et al, 2014) (Fig 3F; Supplementary Table 12). A specific example is the Arpp-21 gene that leads to aberrant dendritic plasticity when down-regulated (Rehfeld et al, 2018) and has been genetically linked to intellectual disability (Marangi et al, 2013) or the $N p y 2 r$ gene that leads to memory impairment in corresponding knockout mice (Redrobe et al) (Fig EV8). Neuropsin (Klk8) is another gene affected in Setd $1 b$ cKO mice that plays a complex role in memory function. It regulates the extracellular matrix, leads to spatial reference memory impairment when deleted in mice (Tamura et al, 2006) and has been implicated with mental diseases (Bukowski et al, 2020) (Fig EV8).

In summary, our data further suggest that SETD1B controls a specific set of genes that are characterized by a broad $\mathrm{H} 3 \mathrm{~K} 4 \mathrm{me} 3$ peak at the TSS, are highly expressed in hippocampal excitatory neurons under basal conditions and play a specific role in synaptic plasticity. 


\section{Comparison of epigenetic neuronal gene expression in Kmt2a, Kmt2b and Setd1b cKO mice}

To further elucidate the role of Setdlb in the regulation of neuronal gene expression we decided to compare the data from Setdlb cKO mice to those from other mammalian H3K4 KMTs. We have previously generated comparable H3K4me3 and H3K4me1 ChIP-Seq data from neuronal nuclei obtained from the hippocampal CA region of conditional knockout mice that lack either Kmt $2 a$ or $K m t 2 b$ from excitatory forebrain neurons using the same CRE-line as employed in this study (Kerimoglu et al., 2017). Since these experiments were performed at different timepoints we reanalyzed in parallel the H3K4me3 and H3K4me1 ChIP-Seq datasets obtained from hippocampal neuronal nuclei of $K m t 2 a, K m t 2 b$ and Setdlb cKO mice (cut off adjusted p-value $<0.1 \&$ fold change| > 1.2) to ensure reliable comparison.. In line with the previous findings, all 3 KMT mutant mice exhibit a substantial number of TSS regions $\underline{(+/-2 \mathrm{~kb})}$ with decreased H3K4me3 (adjusted pvalue $<0.1 \&$ fold change $<-1.2$ ) (Fig 4A; Supplementary Tables 13-15). Interestingly, we also detected TSS regions with decreased H3K4me1 in all mutant mice, but only in Setdlb cKO mice a substantial number of TSS regions exhibited increased H3K4me1 (Fig 4B; $\underline{\text { Supplementary Tables }}$ 16-18). In addition, there was little overlap amongst the TSS regions with decreased H3K4me3 in $K m t 2 a, K m t 2 b$ and Setd $1 b \underline{\mathrm{cKO}}$ mice, providing further evidence that Setdlb controls a unique gene expression program in neuronal cells (Fig 4C). To test this hypothesis directly, we decided to compare the corresponding gene expression changes in the hippocampal CA region of the 3 different KMT cKO mice. While the ChIP-seq data available for $K m t 2 a$ and $K m t 2 b \_$cKO mice had been generated from neuronal nuclei, the corresponding gene expression analysis represents RNA-seq data obtained from bulk tissue of the hippocampal CA region (Kerimoglu et al., 2017). To ensure optimal comparison of these RNA-seq data to the gene expression changes in Setdlb cKO mice, we also performed RNA-seq from the whole tissue of the hippocampal CA region of Setdlb cKO mice and control littermates. We observed $\underline{486}$ genes that were significantly downregulated (adjusted p-value < $\underline{0.1 \& \text { fold change }<-1.2)}$ when comparing control to Setdlb cKO mice (Fig 4D; Supplementary

Table 19). The majority of those genes were also detected via neuronal specific RNA-seq in Setdlb cKO mice that we performed before (see above) (Fig EV9). While the total number of genes downregulated in the hippocampal CA region of $K m t 2 a, K m t 2 b$ and Setdlb cKO mice was comparable, there was little overlap amongst them (Fig 4E; Supplementary Tables 19-21). Recently, RNA-sequencing data was reported for mice that were heterozygous for Setdla. Although these mutants were heterozygous constitutive knock-out mice and furthermore cortical tissue was analyzed instead of the hippocampus (Mukai et al, 2019), it is interesting to note that there was virtually no overlap regarding the genes downregulated in Setdla knock-out mice, when compared to the data obtained from our Setdlb cKO mice (Fig. EV10). Further support for a distinct role of Setdlb in neuronal gene expression was revealed by the finding that the genes downregulated in Setdl $b$ cKO mice exhibited a significant enrichment for neuron-specific genes, while this was not the case for 
bioRxiv preprint doi: https://doi.org/10.1101/2021.08.02.454636; this version posted August 2, 2021. The copyright holder for this preprint (which was not certified by peer review) is the author/funder, who has granted bioRxiv a license to display the preprint in perpetuity. It is made available under aCC-BY-ND 4.0 International license.

genes downregulated in $K m t 2 a \mathrm{cKO}$ or $K m t 2 b \mathrm{cKO}$ mice (Fig 4F; Fig EV11). While we observed that genes downregulated in $\mathrm{Kmt} 2 a$ or $\mathrm{Km} 2 \underline{\mathrm{b}} \mathrm{cKO}$ mice also display decreased H3K4me3 at the TSS (Fig 4G), only the genes downregulated in Setdlb cKO mice were characterized by reduced H3K4me3 and also increased H3K4me1 at their TSS (Fig 4G). Consequently, the genes that concomitantly exhibited decreased H3K4me3 levels and were downregulated in Setd1b cKO mice displayed significantly broader H3K4me3 peaks at the TSS (Fig $\mathbf{4 H}$ ) and were expressed at higher levels under basal conditions when compared to the genes controlled by $\underline{\operatorname{Kit} 2 a}$ or $\underline{\operatorname{Kmt} 2 b}$ (Fig $\mathbf{4 I}$; Supplementary Tables 22 and 23 ).

The fact that under basal conditions genes regulated by Setdlb exhibit a wider H3K4me3 distribution at the TSS compared to those regulated by the other two KMTs suggests that Setd1b spends more time at the TSS and therefore moves further downstream, which is in line with the suggested mode of action for H3K4 KMTs (Soares et al., 2017). This view is further supported by our observation that the number of genomic regions with decreased H3K4me3 was similar in Kmt2a, $\underline{K m t 2 b}$ and Setd $1 b \mathrm{cKO}$ mice when we analyzed the first $2 \mathrm{~kb}$ downstream of the TSS (Fig EV12A, B). However, significantly more regions were affected in Setdlb cKO mice when we analyzed the region $5 \mathrm{~kb}$ downstream the TSS (Fig EV12B). In turn, the genomic regions showing decreased

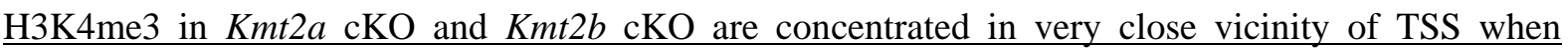
compared to the regions affected in Setdlb cKO mice (Fig EV12C-E). These data also support the view that Setd $1 b$ promotes efficient tri-methylation of $\mathrm{H} 3 \mathrm{~K} 4$ at genes that already underwent monomethylation by other KMTs.

In line with our data showing that the genes affected in $K m t 2 a, K m t 2 b$ and Setdlb cKO mice substantially differ, functional GO category analysis revealed that genes affected in the $3 \mathrm{KMT} \underline{\mathrm{cKO}}$ mice also represent different functional categories. When compared to the genes affected in Kmt2a or $K m t 2 b$ cKO mice, genes that were downregulated and concomitantly exhibited decreased H3K4me3 in Setdlb cKO mice represent pathways intimately linked to learning and memory and the function of hippocampal excitatory neurons such as "regulation of behavior", or "memory" Supplementary Table 24). Further analysis revealed that the genes affected in Kmt2a cKO mice also partly relate to neuronal plasticity functions (Fig EV13A; Supplementary Table 24) while the genes affected in $K m+2 b$ cKO mice represent almost exclusively pathways important for basal cellular function such as metabolic processes (Fig EV13B; Supplementary Table 24). We also compared the

292 genes with significantly reduced H3K4me3 at the TSS region (+/- $2 \mathrm{~kb})$ among the three KMT cKOs and a study that analyzed H3K4me3 in bulk hippocampus tissue of a mouse model for Alzheimer's disease (Gjoneska et al., 2015). Interestingly, the overlap was significantly higher for Setdlb cKO mic (Fig EV14).

In summay, our observations so far support the view that the Setdlb, Kmt $2 a$ and $K m t 2 b$ serve distinct functions in excitatory hippocampal neurons oft the postnatal brain and that among them

298 Setdlb might be the most relevant for the regulation of learning processes. In line with this, 
bioRxiv preprint doi: https://doi.org/10.1101/2021.08.02.454636; this version posted August 2, 2021. The copyright holder for this preprint (which was not certified by peer review) is the author/funder, who has granted bioRxiv a license to display the preprint in perpetuity. It is made available under aCC-BY-ND 4.0 International license.

comparison of hippocampus-dependent learning in Setd1b, Kmt $2 a$ and $K m t 2 b$ cKO mice in the Morris water maze task, suggest that learning impairment is more pronounced in Setdlb cKO mice (Fig EV15A). To further elucidate the distinct roles of Setd1b, Kmt2a and Kmt2b we hypothesized that they might be expressed in different neuronal subtypes. Therefore, we isolated the hippocampus from 3-month-old wild type mice, sorted the nuclei and performed single nuclear (snuc) RNA-seq (Fig EV15B). We were able to detect all major cell types of the hippocampus and found $K m+2 a, K m t 2 b$ and Setdlb as well as the other three H3K4 KMTs to be expressed in all of these cell types (Fig EV15C). We did not observe any particular neuronal cell type with especially high Setdlb expression (Fig EV15D). Interestingly, the snucRNA-seq data revealed higher Kmt $2 a$ expression when compared to Setd $1 b$ and $K m t 2 b$ across cell types including excitatory neurons of the CA region, an effect that was not due to the total amount of reads detected per cell (Fig EV15C, D). These data were confirmed via RNAscope. Thus, when we analyzed the pyramidal neurons of the hippocampal CA region, we observed significantly more transcripts/cell for Kmt $2 a$ when compared to Kmt2b or Setdlb (Fig EV15E). In summary, these data may suggest that highly expressed enzymes such as Kmt2a are essential to ensure neuronal H3K4 methylation sufficient for basal and neuron-specific cellular processes and that the additional expression of enzymes such as Setdlb is essential to further promote H3K4me3 at genes particularly important for neuronal functions like synaptic plasticity.

\section{DISCUSSION}

We show that postnatal loss of Setdlb from excitatory forebrain neurons impairs learning in mice when measured in the hippocampus-dependent water maze paradigm. These data are in line with previous findings showing that hippocampal $\mathrm{H} 3 \mathrm{~K} 4 \mathrm{me} 3$ increases in response to memory training in rodents (Gupta et al., 2010), while its levels are reduced in the hippocampus of a mouse for AD-like neurodegeneration (Gjoneska et al., 2015) and in postmortem human brain samples of patients suffering from cognitive diseases (Shulha et al, 2012). Our data furthermore support previous genetic studies linking mutations in Setdlb to intellectual disability (Labonne et al., 2016) (Hiraide et al., 2018) (Roston et al., 2020). Although spatial reference memory measured in the water maze paradigm critically depends on hippocampal function, it is important to note that Setdlb deletion is not specific to the hippocampus and that we cannot exclude that other brain regions and subtle changes in postnatal development may also contribute to the observed phenotype. Impaired hippocampusdependent memory has also been observed in mice that lack Kmt2a (Gupta et al., 2010) (Kerimoglu et $a l ., 2017$ ) or $K m+2 b$ (Kerimoglu et al., 2013) from excitatory neurons of the postnatal forebrain. Our comparative analysis suggests, however, that the effect is most severe in Setdlb cKO mice. Interestingly, mice heterozygous for Setdla, the close homologue to Setdlb that is genetically linked to schizophrenia, show no impairment in the water maze task but rather exhibit impaired working memory and schizophrenia-like phenotypes (Mukai et al., 2019). Distinct roles for Setdlb and Setdla are also reported for other cellular system (Bledau et al, 2014) (Arndt et al, 2018; Brici et al, 2017; 
bioRxiv preprint doi: https://doi.org/10.1101/2021.08.02.454636; this version posted August 2, 2021. The copyright holder for this preprint (which was not certified by peer review) is the author/funder, who has granted bioRxiv a license to display the preprint in perpetuity. It is made available under aCC-BY-ND 4.0 International license.

336 Kranz \& Anastassiadis, 2020; Schmidt et al, 2018). These data suggest that the different H3K4

337 KMTs, and at least Kmt2a, Kmt2b, Setdla and Setdlb, likely serve distinct functions in the postnatal

338 brain. It will therefore be important to eventually generate corresponding and comparable data for all $\underline{\text { six H3K4 KMTs. }}$

340 The molecular characterization of Setdlb cKO further confirms this view. Here, we focused

341 on the analysis of the hippocampus, since this brain region is critical for spatial reference memory

342 which was severely impaired in Setd1b cKO mice. It will nevertheless be interesting to study other

343 brain regions such as the prefrontal cortex in future experiments. In line with the role of Setdlb in

344 regulating H3K4me3, we observed a substantial decrease of neuronal H3K4me3 levels and the vast

345 majority of these changes were observed close to TSS regions. Many genes with decreased H3K4me3

346 also exhibited reduced $\mathrm{H} 3 \mathrm{~K} 9 \mathrm{ac}$, which is in line with previous data showing that $\mathrm{H} 3 \mathrm{~K} 4 \mathrm{me} 3$ appears to

347 be a pre-requisite for H3K9ac, most likely since H3K4 KMTs interact with histone acetyltransferases

348 (Kerimoglu et al., 2013) (Mishra et al, 2014) (Wang et al, 2009). For example, SETD1B and the

349 histone-acetyltransferase KAT2A were shown to interact with WDR5, a central component of H3K4

350 KMT complexes (Lin et al, 2016) (Ma et al, 2018), which is interesting since loss of Kat2a from

351 excitatory forebrain neurons also leads to severe impairment of spatial reference memory (Stilling $e t$

352 al., 2014).

353 Our finding that H3K4me1 levels were increased at a substantial number of TSS regions that

354 exhibited decreased H3K4me3 in Setd1b cKO mice suggests that H3K4 mono-methylation at the TSS

355 regions of the affected genes is likely mediated by other KMTs in addition to Setd1b. This is in

356 agreement with increasing evidence suggesting that the different H3K4 KMTs exhibit some

357 specificity towards mono- di- or tri-methylation. However, specificity likely depends on the cellular

358 context and care has to be taken when interpreting the different in vitro and in vivo data. Nevertheless,

359 our data are in line with studies showing that SETD1B preferentially mediates H3K4-trimethylation

360 when compared to the other KMTs such as KMT2A and KMT2B that are believed to mediate mono-

361 and di-methylation with comparatively low H3K4 tri-methylation activity_(Wu et al, 2008) (Lee \&

362 Skalnik, 2008) (Shinsky et al, 2015) (Bochyńska et al., 2018; Rao RC, 2015) (Kranz \& Anastassiadis,

363 2020).

364 In agreement with these findings, we show that neuronal H3K4me1 is exclusively reduced in

$365 \quad K m t 2 a$ and $K m t 2 b$ cKO. Since H3K4me3 is similarly reduced in these cKO mice, our data suggest

366 that neuronal KMT2A and KMT2B can also catalyze H3K4 tri-methylation. In such a scenario,

367 SETD1B might act in concert with other KMTs to further facilitate H3K4me3 at specific genes. This

368 might also explain our finding that genes affected in Setd1b cKO mice exhibit the widest H3K4me3

369 distribution at their TSS and the highest RNA expression levels under basal conditions. A broad

370 H3K4me3 peak around TSS is indicative of higher transcriptional frequency and RNA expression

371 levels and has thus been linked to the expression of genes that are of particular importance for a given

372 cell type (Benayoun et al., 2015) (Park S, 2020). This is in line with our observation that genes 
bioRxiv preprint doi: https://doi.org/10.1101/2021.08.02.454636; this version posted August 2, 2021. The copyright holder for this preprint (which was not certified by peer review) is the author/funder, who has granted bioRxiv a license to display the preprint in perpetuity. It is made available under aCC-BY-ND 4.0 International license.

373 decreased in hippocampal neurons in Setd1b cKO mice are characterized by a broad H3K4me3 peak 374 and represent functional pathways critically involved in synaptic plasticity and learning \& memory. In 375 agreement with this a recent study showed that memory training specifically activates hippocampal 376 genes with broad H3K4me3 peaks at the TSS (Collins et al, 2019). It is therefore interesting to note 377 that the genes affected in Setdlb cKO mice not only showed a broader H3K4me3 peak and higher 378 expression when compared to the genes affected in $K m t 2 a$ or $K m+2 b \mathrm{cKO}$ mice but that also memory 379 performance in the water maze training was more severely affected in Setdlb cKO mice when 380 compared to mice lacking $K m+2 a$ or $K m t 2 b$. These data are also in line with a recent study in mouse embryonic stem cells in which SETD1B was associated with the regulation of highly expressed genes that exhibit a broad $\mathrm{H} 3 \mathrm{~K} 4 \mathrm{me} 3$ peak, while KMT2B was linked to the expression of genes with narrow H3K4me3 peaks (Sze et al, 2020). Interestingly, that study suggested a functional redundancy of Setdlb and Setdla. However, our data suggest that this is not the case in post-mitotic neurons. Moreover, mutations in either Setdla or Setdlb lead to distinct neuropsychiatric diseases and unlike Setdlb cKO mice, Setdla heterozygous mutant mice do not exhibit impairment of long-term memory consolidation (Mukai et al., 2019).

These findings may suggest that among the three H3K4 KMTs studied here, Kmt2a and $\underline{K m t 2 b}$ are essential to ensure the sufficient expression of genes important for basal cellular processes and in the case of Kmt2a also specific neuronal functions. The additional presence of $\underline{\operatorname{Setd} 1 b}$ may further facilitate $\mathrm{H} 3 \mathrm{~K} 4 \mathrm{me} 3$, thereby enabling the preeminent expression of genes specific for hippocampal excitatory neuronal function.

At present we cannot conclusively answer the question how Setdlb affects the expression of a specific set of hippocampal_genes. Our snucRNA-seq analysis showed that Setdlb is expressed at $\underline{\text { similar levels in all types of excitatory neurons of the hippocampal CA region suggesting that its }}$ specific function of facilitating learning behavior is not driven by its expression in a specific neuronal subtype. The fact that loss of either Kmt2a,Kmt2b or Setdlb leads to distinct changes in neuronal gene-expression might also be due to the specific subunit compositions of the KMT complexes. Previous data suggest that H3K4 KMTs associate with different co-activators (Yokoyama et al, 2004) (Scacheri et al, 2006) (Lee et al, 2006) (Dreijerink et al, 2006) (Shilatifard, 2012) (Bochyńska et al.. 2018) (Kranz \& Anastassiadis, 2020). While all H3K4 KMTs are believed to interact with a number of core subunits (Kranz \& Anastassiadis, 2020), data from other cell types than neurons show that

403 KMT2A and KMT2B can bind the transcriptional regulator multiple endocrine neoplasia type 1 404 (Menin) (Hughes et al, 2004). In contrast, SETD1B was shown to interact with CXXC finger protein 1 (CFP1) and WDR82 which binds to RNA-polymerase II. This is in line with data suggesting that SETD1A and SETD1B are the major KMTs found at TSS regions (Bi et al, 2011; Deng et al, 2013).

Future studies will need to further explore this possibility. It is however, interesting to note 408 that the genes with decreased H3K4me3 in the hippocampus of Kmt2a or Kmt $2 b \mathrm{cKO}$ mice were 409 enriched for binding sites of ETS and E2F transcription factors, respectively (Kerimoglu et al., 2017). 
bioRxiv preprint doi: https://doi.org/10.1101/2021.08.02.454636; this version posted August 2, 2021. The copyright holder for this preprint (which was not certified by peer review) is the author/funder, who has granted bioRxiv a license to display the preprint in perpetuity. It is made available under aCC-BY-ND 4.0 International license.

410 In case of Setd1b cKO mice we observed an enrichment for REST, a key transcription factor 411 inhibiting the expression of neuron-specific genes (Hwang \& Zukin, 2018). This observation may 412 help to understand why loss of Setdlb mainly affected the expression of neuron-specific genes 413 important for memory function. While future research should aim to further elucidate the specific role 414 of SETD1B, it is interesting to note that the H3K4 Demethylase KMD5C was found to regulate REST 415 target genes (Tahiliani et al, 2007).

416 Taking into account that decreased neuronal H3K4me3 levels have been observed in 417 cognitive and neurodegenerative diseases, therapeutic strategies that reinstate specifically the 418 expression of neuronal plasticity genes controlled by SETD1B might be particularly helpful. We 419 suggest that the epigenetic drugs currently tested in pre-clinical and clinical settings for cognitive 420 diseases should also be analyzed for their potential to reinstate the H3K4me3 peak width at the TSS 421 of genes linked to neuronal function and learning behavior.

422 The aim of this study was to analyze the role of Setd $1 b$ on learning behavior when deleted 423 postnatally and to explore its impact on epigenetic gene expression and compare these data to findings 424 obtained from postnatal deletion of $K m t 2 a$ and $K m t 2 b$. While we observe that Setd $1 b$ is required for 425 memory function and controls the expression of genes linked to neuronal plasticity, it will be 426 important to study the functional and structural consequences in the corresponding neuronal networks.

427 At present such data is rare. A recent study employed heterozygous Kmt $2 a$ constitutive knockout mice 428 and found decreased dendritic spine density in the ventral hippocampal CA1 region (Vallianatos et al, 429 2020). To compare the role of the different H3K4 KMTs in synaptic morphology and network activity 430 during development and in the postnatal brain is thus an important task for future research.

$431 \quad$ In summary, we identify H3K4 methyltransferase Setdlb as a crucial factor regulating genes 432 important for hippocampal excitatory neuronal function, which are involved in synaptic plasticity and 433 learning.

434

MATERIALS AND METHODS

436

437 Animals

438 All animals used in this study were of the same genetic background (C57BL/6J ) mice and of 3-6 439 months of age. The experimental groups were age and sex matched. Mice were kept in standard home 440 cages with food and water provided ad libitum. All experiments were performed according to the 441 animal protection law of the state of Lower Saxony. The CRE mice were first described by 442 Minichiello et al (Minichiello et al., 1999) and were used in previous studies related to Kmt2a and 443 Kmt2b (Kerimoglu et al., 2013) (Kerimoglu et al., 2017). Deletion of the target gene is restricted to 444 the forebrain excitatory neurons and is initiated upon postnatal day 21. 


\section{Behavior experiments}

446 Water maze: The behavioral experiments were performed as described previously (Kerimoglu et

447 al., 2017). For in depth feature analysis from water maze data, a modified version of MUST-C

448 algorithm was used (Illouz et al., 2016) (Islam et al., 2021). In brief, different strategies were

449 defined based on trajectories mice employed in each trial. Cumulative score for hippocampal

450 dependent strategy score was calculated as follow:

$$
\underline{\text { mean cumulative strategy score }=\frac{1}{n} * \sum_{i=1}^{n}\left[\frac{S d f i * S d c}{m c}+\frac{S s c f i * S s c c}{m c}+\frac{S l c f i * S l c c}{m c}\right]}
$$

$\underline{n=\text { total trial number }}$

$455 \quad \mathrm{Sdf}_{\mathrm{i}}=$ Frequency of direct strategy in $\mathrm{i}^{\text {th }}$ trial

$456 \quad \underline{\mathrm{Sdc}}=$ given strategy score for direct search; 10

$457 \quad \mathrm{mc}=$ total number of mice

$458 \quad$ Sscf $_{i}=$ Frequency of short chaining in $i^{\text {th }}$ trial

$459 \quad$ Sscc = given strategy score for short chaining search; 9.5

$460 \quad$ Slcf $_{i}=$ Frequency of short chaining in $i^{\text {th }}$ trial

$461 \quad$ Slcc= given strategy score for long chaining search; 7

462

$463 \quad$ Y-maze \& Open field: The open field tests were performed as described previously (Islam et al.,

464 2021). Working memory was accessed with a Y-shaped plastic runway $(10 \mathrm{x} 40 \mathrm{~cm}$ arms, walls 40

465 cm high). The mouse was placed into the Y-maze in the triangle-shaped central platform and left to

466 freely explore the maze for $5 \mathrm{~min}$ \% of spontaneous alterations (choice of "novel" arm: when animal

467 goes into different arm then before) was recorded and scored via a videosystem (TSE).

\section{Tissue isolation and processing}

470 ChIP-Seq and bulk RNA-Seq experiments from NeuN (+) nuclei were performed from the 471 hippocampal cornu ammonis (CA) region, which consists of the hippocampus without the dentate 472 gyrus and was isolated as described before (Kerimoglu et al., 2013) (Kerimoglu et al., 2017). For 473 single nuclear RNA-sequencing whole hippocampal tissue was isolated. The tissues were dissected and flash frozen in liquid nitrogen and stored at $-80^{\circ} \mathrm{C}$ until further processing.

\section{Cell-type specific nuclear RNA isolation and sequencing}

Frozen CA tissues from the left and right hemisphere of two mice were pooled together and processed on ice to maintain high RNA integrity. Tissue was homogenized using a plastic pestle in a 1.5mL Eppendorf tube containing $500 \mathrm{uL}$ EZ prep lysis buffer (Sigma, NUC101-1KT) with 30 strokes. The homogenate was transferred into $2 \mathrm{~mL}$ microfuge tubes, lysis buffer was added up to 2 $\mathrm{mL}$ and incubated on ice for 7 minutes. After centrifuging for 5 minutes at $500 \mathrm{~g}$, the supernatant was removed and the nuclear pellet was resuspended into $2 \mathrm{~mL}$ lysis buffer and incubated again on ice (7 
483

484

485

486

487

488

489

490

491

492

493

494

495

496

497

498

499

500

501

502

503

504

505

506

507

508

509

510

511

512

513

514

515

516

517

518

519

minutes). After centrifuging for 5 minutes at $500 \mathrm{~g}$, the supernatant was removed and the nuclei pellet was resuspended into 500ul nuclei storage buffer (NSB: 1x PBS; Invitrogen, 0.5\% RNase free BSA;Serva, 1:200 RNaseIN plus inhibitor; Promega, 1x EDTA-free protease inhibitor; Roche) and filtered through $40 \mu \mathrm{m}$ filter (BD falcon) with additional $100 \mu \mathrm{L}$ NSB to collect residual nuclei from the filter. Nuclei were stained with anti-NeuN-Alexa488 conjugated antibody (1:1000) for 45 minutes and washed once with NSB. Stained nuclei were then FACS-sorted with FACSaria III using $85 \mu \mathrm{m}$ nozzle. Nuclei were gated by their size, excluding doublets and neuronal nuclei were separated from non-neuronal nuclei by their NeuN-Alexa488 fluorescence signal. Sorted nuclei were collected into a $15 \mathrm{~mL}$ falcon tube precoated with NSB, spun down and RNA was isolated using Trizol LS. After addition of chloroform according to the Trizol LS protocol, aqueous phase was collected and RNA was isolated by using Zymo RNA clean \& concentrator-5 kit with DNAse treatment. Resulting RNA concentration were measured in Qubit and RNA-seq was performed using 100ng of neuronal RNA with illumina TruSeq RNA Library Prep Kit. Since glial nuclei are smaller and contains very little amount of RNA, neuronal nuclear RNA was scaled down and 1ng from both neuronal and glial nuclear RNA was used to make RNA-seq libraries using Takara SMART-Seq v4 Ultra Low Input RNA Kit. Libraries were sequenced using single-end 75 bp in Nextseq 550 or single-end 50 bp in HiSeq 2000, respectively.

\section{Cell-type specific chromatin isolation and ChIP sequencing}

Frozen tissues were homogenized, formaldehyde (1\%) fixed for 10 minutes and quenched with $125 \mathrm{mM}$ glycine for 5 minutes. Debris was removed by sucrose gradient centrifugation. The resulting nuclear pellet was stained with anti-NeuN-Alexa488 conjugated antibody (1:1000) for 25 minutes and washed 3 times with PBS. Stained nuclei were then FACS sorted with FACSaria III using $85 \mu \mathrm{m}$ nozzle. Nuclei were gated similarly as described previously (Halder et al, 2016). Sorted nuclei were collected into a $15 \mathrm{~mL}$ falcon tube and transferred into $1.5 \mathrm{~mL}$ tubes. The nuclear pellet was flash frozen in liquid nitrogen and saved at $-80^{\circ} \mathrm{C}$ for further processing. For chromatin shearing, the pellet was resuspended into 100uL RIPA buffer (containing 1\% SDS) and sonicated for 25 cycles in Diagenode bioruptor plus with high power and 30 cycles on/ 30 cycles off. Chromatin shearing was checked by taking a small aliquot and decrosslinking the DNA by 30 minutes RNAse and 2 hours of proteinase K treatment. DNA was isolated using SureClean Plus protocol. Sheared chromatin size was determined using Bioanalyzer 2100(DNA high sensitivity kit) and the concentration was measured using Qubit 2.0 fluorometer (DNA high sensitivity kit). 0.3 $\mu$ g chromatin was used along with $1 \mu \mathrm{g}$ of antibody to do ChIP for H3K4me3 (Abcam ab8580), H3K4me1 (Abcam ab8895), H3K27ac (Abcam ab4729) and H3K9ac (Millipore 07-352). ChIP was performed as previously described (Halder et al., 2016). The resulting ChIP DNA was subjected to library preparation using NEBNext Ultra II DNA library preparation kit and sequenced for single end 50 bp at illumina HiSeq 2000. 


\section{ChIP-Seq Analysis}

521 Pre-Processing, Profile Plots, Peak Calling, Differential Binding Analysis, Annotation, Motif

522 Enrichment Analysis and Visualization

Base calling and fastq conversion were performed using Illumina pipeline. Quality control was performed using fastqc (www.bioinformatics.babraham.ac.uk/projects/fastqc). Reads were mapped to mm10 mouse reference genome with STAR aligner v2.3.0.w. PCR duplicates were removed by rmdup -s function of samtools $\underline{(\mathrm{Li} \text { et al, 2009)}}$. BAM files with unique reads belonging to the same group were merged into a single BAM file with the merge function of samtools. Profile plots were created from these merged BAM files with NGSPlot (Shen et al, 2014).

Peak calling was performed using MACS2 (Feng et al, 2012) against the input corresponding to the particular group (i.e., control or $\mathrm{cKO}$ ) using $\mathrm{q}<0.1$. Consensus peaksets were generated for each histone modification individually using the Diffbind package of Bioconductor (Ross-Innes et al, 2012 ) with the command dba.count and the parameter minOverlap $=1$. Then, these consensus peaksets were intersected with each other using the intersect function of bedtools with default parameters, providing one common peakset representing all four histone modifications. The differential binding analysis for each histone mark between control and Setdlb cKO was then performed using Diffbind (Ross-Innes et al., 2012) with this common peakset as input.

For the comparison of $\mathrm{H} 3 \mathrm{~K} 4 \mathrm{me} 3$ changes in $K m t 2 a \mathrm{cKO}, K m t 2 b \mathrm{cKO}$ and Setdlb cKO common peaksets for each individual histone mark from three separate ChIP-Seq experiments were extracted in the same way as above. In this case, first, consensus peaksets for a histone mark from each individual ChIP-Seq experiment (i.e., "Control vs Kmt2a cKO", "Control vs Kmt $2 b$ cKO" and "Control vs Setdlb cKO") were determined using Diffbind as above. Then, these consensus peaksets were intersected with each other as above, and as a result we obtained a set of common regions detected in all three independent experiments that possess H3K4me3 mark. For the purpose of comparing the effects of the three KMT knockdowns on H3K4me3, the differential binding analysis for each individual ChIP-Seq experiment was performed using this common peakset as input.

We also wanted to compare the changes in $\mathrm{H} 3 \mathrm{~K} 4 \mathrm{me} 1$ in these three KMT cKO mice. But additionally, based on our prior observations from Setdlb cKO mice, we wanted to also investigate the interplay between $\mathrm{H} 3 \mathrm{~K} 4 \mathrm{me} 3$ and $\mathrm{H} 3 \mathrm{~K} 4 \mathrm{me} 1$, and whether it differs between the three KMT cKO mice. We therefore first came up with the common peakset for H3K4me1 from all three ChIP-Seq

550 experiments as described above. Then, we intersected this common H3K4me1 peakset with the common H3K4me3 peakset and came up with a peakset representing regions containing both H3K4me3 and H3K4me1 marks in all three separate experiments ("me3 me1 3 kmt ckos"). The differential binding analyses and comparisons relating to H3K4me1 in the three KMT cKOs were performed using "me3 me1 3 kmt ckos" as input. Diffbind package was used for differential

555 binding analysis with in-built DESEQ2 option for differential analysis (Ross-Innes et al., 2012). For 556 the initial analysis of Setd $1 b$ cKO alone we used the cut-off "adjusted p-value $<0.05 \&$ fold change| 
558 Setd $1 b$ cKO mice we used a more lenient cut-off - "adjusted p-value $<0.1 \& \mid$ fold change $\mid>1.2$ " in

559 order to avoid missing out on overlaps and/or common trends that might be biologically relevant. The

560 annotation of the genomic regions and transcription factor motif enrichment analysis were performed

561 with HOMER (Heinz et al, 2010). ChIPSeeker package of Bioconductor (Yu et al, 2015) was used to

562 calculate the proportion of the types of genomic regions in a given set and to create corresponding pie

563 charts. Graph Pad Prism was used to generate violin plots. Outliers were removed using the Rout

564 methods $(\mathrm{Q}=1 \%)$ in GraphPad Prism. Integrated Genome Browser (IGB) was used to make

565 visualizations representing the distribution of histone marks and RNA expression over selected genes

566 (Nicol et al, 2009).

568 Obtaining H3K4me3 Width at Promoters

569 1. For Promoters with Decreased H3K4me3 and Different H3K4me1 Trends at TSS Proximal Regions $570 \quad$ in Setd1b cKO

571 First, we performed differential binding analysis in "Control vs Setdlb cKO" for H3K4me3 and 572 H3K4me1 using the "me3/me1/k9ac/k27ac common peakset". Then we extracted the TSS proximal 573 regions (+/- $2000 \mathrm{bp}$ from TSS) with significantly decreased H3K4me3 in Setd1b cKO (adjusted p574 value $<0.05 \&$ fold change $<-1.5)$. These TSS proximal regions were then separated into three 575 groups depending on the concomitant change of H3K4me1; (i) increased H3K4me1 (fold change > 576 1.5), (ii) decreased H3K4me1 (fold change <-1.5) and (iii) not changed H3K4me1 (the rest). Then 577 each of these TSS proximal regions was intersected to the consensus H3K4me3 peakset with bedtools

578 using intersect function with the option " $-u$ ". The latter option ensures that the full original feature in 579 the first input (in this case always the H3K4me3 peakset), not just the overlapping portion, is reported 580 once the overlap is found. In this way the full extent of H3K4me3 distribution around the target 581 genomic region can be appreciated. Finally, the width was calculated by subtracting chromosome start 582 coordinates from chromosome end coordinates and adding 1 (chromosome end - chromosome start + 583 1).

\section{For Promoters with Decreased H3K4me3 at TSS Proximal Regions in Different KMT cKOs}

586 For the purpose of comparison between the three KMT cKO mice we chose a more lenient cut-off 587 (adjusted $\mathrm{p}$-value $<0.1 \&$ fold change $<-1.2$ ) in order to avoid as much as possible excluding 588 genomic regions showing the same trend but not making it past the threshold in some of the cases. 589 The TSS proximal regions (+/- 2000 bp) with significantly decreased H3K4me3 in each KMT cKO 590 were overlapped to the consensus H3K4me3 peakset using intersect $-u$. Again, in this way we were 591 able to capture the full extent of H3K4me3 around the selected target regions. The width at the 592 resulting region was then calculated by chromosome end - chromosome start +1 . A random list of the 593 same size was also generated from the TSS proximal regions with unchanged H3K4me3 for each 
cKO using the same procedure. The criteria for unchanged $\mathrm{H} 3 \mathrm{~K} 4 \mathrm{me} 3$ were adjusted $\mathrm{p}$-value $>0.5 \&$

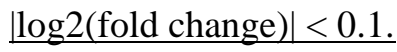

596

\section{For Downregulated Genes}

598 Again, to obtain a more comprehensive view of downregulation of gene expression and its

599 concordance with peak width we chose a more lenient cut-off; adjusted p-value $<0.1 \&$ fold change $<$

$600 \quad \underline{-1.2}$.

601 From the consensus H3K4me3 peakset the promoter regions were selected and annotated for their

602 gene names using HOMER. To capture the whole extent of H3K4me3 along the promoters as much

603 as possible, we used the default standard for promoter identification implemented by ChIPSeeker $(+/-$

$6045000 \mathrm{bp} ;$ see above). From the resulting annotated file the promoter regions belonging to significantly

605 downregulated genes were extracted and the widths were calculated as above. In each case, a random

606 list of the same size from genes with unchanged expression was also generated using the same

607 procedure. The criteria for unchanged expression were adjusted p-value $>0.5 \& \mid \log 2$ (fold change) $\mid<$

$608 \quad \underline{0.1}$

610 4. For the Genes with Both Decreased TSS Proximal H3K4me3 and Downregulated Expression in

\section{Different KMT cKOs}

612 The bed files generated in Section 2 by the overlap of the consensus H3K4me3 peakset with TSS

613 proximal regions having significantly decreased H3K4me3 were annotated for gene names using

614 HOMER. From the resulting annotated file the genomic coordinates belonging to the downregulated

615 genes were extracted and the widths were calculated. Again, in each case a random list of the same

616 size containing genes with unchanged expression and H3K4me3 was selected using the same

617 procedure and the same criteria as above.

618

619 RNA-Seq Analysis

620 Base calling, fastq conversion, quality control, mapping of reads were performed as described before

621 (Kerimoglu et al., 2017). Bulk RNA-Seq was mapped with STAR on the whole genome and reads

622 were counted with featureCounts thus considering spliced as well as unspliced transcripts. Differential

623 expression was analyzed with DESeq2 package of Bioconductor (Love et al, 2014). RPKM values

624 were calculated using edgeR package of Bioconductor. We used the cut-off "adjusted p-value $<0.1 \&$

625 fold change $\mid>1.2$ " to determine significance.

626

627 Functional GO Enrichment Analysis

628 Enrichment for functional GO categories was performed with the topGO package of Bioconductor

629 (https://bioconductor.org/packages/release/bioc/html/topGO.html), using the weighted analysis

630 option as described in the manual with default settings. As a result, a weighted p-value for each GO 
bioRxiv preprint doi: https://doi.org/10.1101/2021.08.02.454636; this version posted August 2, 2021. The copyright holder for this preprint (which was not certified by peer review) is the author/funder, who has granted bioRxiv a license to display the preprint in perpetuity. It is made available under aCC-BY-ND 4.0 International license.

631 category was calculated (described in the manual). In each separate analysis only the GO categories

632 (biological processes) with a weighted $p$-value lower than 0.005 were selected and shown in the

633 figures. All genes in the genome were used as the reference set (i.e., gene universe). The whole list of

634 the GO categories, including the ones highlighted in the figures, can be found in supplemental figures

$635 \quad \underline{7,12}$ and 24.

636

\section{Single-nucleus RNA-Seq}

638 Unfixed NeuN + neuronal nuclei were isolated as mentioned above (section: Cell-type specific nuclear

639 RNA isolation and sequencing). Sorted neuronal nuclei were counted in a Neubauer chamber with

$64010 \%$ trypan blue (in PBS) and nuclei concentration were adjusted to 1000 nuclei $/ \mu \mathrm{L}$. The nuclei were

641 further diluted to capture and barcode either 2000 or 4000 nuclei according to Chromium single cell 3'

642 reagent kit v3 (10X genomics). Single nuclei barcoding, GEM formation, reverse transcription, cDNA

643 synthesis and library preparation were performed according to $10 \mathrm{X}$ genomics guidelines. Finally, the

644 library was sequenced in Illumina NextSeq 550 according to manufacturer's protocol. Gene counts

645 were obtained by aligning reads to the mm10 genome (GRCm38.p4) (NCBI:GCA 000001635.6)

646 using CellRanger software (v.4.0.0) (10XGenomics). The CellRanger count pipeline was used to

647 generate a gene-count matrix by mapping reads to the pre-mRNA as reference to account for

648 unspliced nuclear transcripts. The CellRanger aggr pipeline was used to generate an aggregated

649 normalized gene-count matrix from seven datasets. The final count matrix contained 15661 cells with

650 a mean of 56.150 total read counts over protein-coding genes.

651 The SCANPY package was used for pre-filtering, normalization and clustering (Wolf et al, 2018).

652 Initially, nuclei that reflected low-quality cells (either too many or too few reads, nuclei isolated

653 almost exclusively, nuclei expressing less than 10\% of house-keeping genes (Eisenberg \& Levanon,

654 2013) were excluded remaining in 15656 nuclei. Next, counts were scaled by the total library size

655 multiplied by 10.000 , and transformed to $\log$ space. A total of 3771 highly variable genes were

656 identified based on dispersion and mean, the technical influence of the total number of counts was

657 regressed out, and the values were rescaled. Principal component analysis (PCA) was performed on

658 the variable genes, and UMAP was run on the top 50 principal components (PCs) (Becht et al, 2018).

659 The top 50 PCs were used to build a k-nearest-neighbours cell-cell graph with k=100 neighbours.

660 Subsequently, spectral decomposition over the graph was performed with 50 components, and the

661 Leiden clustering algorithm was applied to identify nuclei clusters. We confirmed that the number of

662 PCs captures almost all the variance of the data. For each cluster, we assigned a cell-type label using 
bioRxiv preprint doi: https://doi.org/10.1101/2021.08.02.454636; this version posted August 2, 2021. The copyright holder for this preprint (which was not certified by peer review) is the author/funder, who has granted bioRxiv a license to display the preprint in perpetuity. It is made available under aCC-BY-ND 4.0 International license.

663

664

665

666

667

668

669

670

671

672

673

674

675

676

677

678

679

680

681

682

683

684

685

686

687

688

689

690

691

692

693

694

695

696

697

698

699

700

701

702

703

704

manual evaluation of gene expression for sets of known marker genes. Violin plots for marker genes were created using the stacked violin function as implemented in SCANPY.

\section{$\underline{\text { RNAscope }}$}

For the detection of Setd1b, Kmt2a and Kmt2b, the RNAscope ${ }^{\circledR}$ Fluorescent Multiplex Assay (ACD Biosystems) was used according to the manufacturer's instructions for fresh-frozen tissue. Briefly, $\underline{\text { mice }(\mathrm{n}=2) \text { were sacrificed by cervical dislocation and the brains were removed quickly, flash-frozen }}$ using liquid nitrogen and embedded in OCT. Then, $20 \mu \mathrm{m}$ coronal sections were cut and stored at $\underline{80^{\circ} \mathrm{C} \text { until further use. For the pre-treatment, the sections were fixed with cold } 10 \% \text { neutral-buffered }}$ formalin at $4^{\circ} \mathrm{C}$ for $15 \mathrm{~min}$ and afterwards dehydrated using 50\%, 70\% and $100 \%$ ethanol. Then, the samples were incubated with Protease IV for $30 \mathrm{~min}$ at RT. The probes were hybridized to the tissue for two hours at $40^{\circ} \mathrm{C}$ using the HybEZTM Humidifying System (ACD Biosystems). Probes were applied to detect Setd1b,Kmt2a or Kmt2b. Positive and negative control probes were also used to control for signal sensitivity and specificity. The probes were then amplified following the manufacturer's protocol. Kmt2a and Kmt2b were labeled with Atto647 and Setdlb with Atto550. Images were obtained on a Leica DMi8 microscope using a 40x air objective and the software CellProfiler (Carpenter et al, 2006) was used for downstream analysis.

\section{Data availability}

GEO accession GSE180326 (token available via editor)

\section{References}

Arndt K, Kranz A, Fohgrub J, Jolly A, Bledau AS, Di Virgilio M, Lesche M, Dahl A, Höfer T, Stewart AF et al (2018) SETD1A protects HSCs from activation-induced functional decline in vivo. Blood 131: 1311-1324

Becht E, McInnes L, Healy J, Dutertre CA, Kwok I, Ng LG, Ginhoux F, Newell EW (2018) Dimensionality reduction for visualizing single-cell data using UMAP. Nature biotechnology, 10.1038/nbt.4314. Advance online publication.

Benayoun BA, Pollina EA, Ucar D, Mahmoudi S, Karra K, Wong ED, Devarajan K, Daugherty AC, Kundaje AB, Mancini E et al (2015) H3K4me3 Breadth Is Linked to Cell Identity and Transcriptional Consistency. Cell 165: 1281-1286

Bi Y, Lv Z, Wang Y, Hai T, Huo R, Zhou Z, Zhou Q, Sha J (2011) WDR82, a key epigenetics-related factor, plays a crucial role in normal early embryonic development in mice. Biol Reprod 84: 756-764 Bledau AS, Schmidt K, Neumann K, Hill U, Ciotta G, Gupta A, Torres DC, Fu J, Kranz A, Stewart $\mathrm{AF}$ et al (2014) H3K4 methyltransferase Setd1a is first required at the epiblast stage, whereas Setd1b becomes essential after gastrulation. Development 141: 1022-1035

Bochyńska A, Lüscher-Firzlaff J, Lüscher B (2018) Modes of Interaction of KMT2 Histone H3 Lysine 4 Methyltransferase/COMPASS Complexes with Chromatin. Cells 7: doi: 10.3390/cells 7030017

Borbély E, Scheich B, Helyes Z (2013) Neuropeptides in learning and memory. Neuropeptides 47: $439-450$ 
bioRxiv preprint doi: https://doi.org/10.1101/2021.08.02.454636; this version posted August 2, 2021. The copyright holder for this preprint (which was not certified by peer review) is the author/funder, who has granted bioRxiv a license to display the preprint in perpetuity. It is made available under aCC-BY-ND 4.0 International license.

Brici D, Zhang Q, Reinhardt S, Dahl A, Hartmann H, Schmidt K, Goveas N, Huang J, Gahurova L, Kelsey G et al (2017) The histone 3 lysine 4 methyltransferase Setd1b is a maternal effect gene required for the oogenic gene expression program. Development 144

Bukowski L, Chernomorchenko AMF, Starnawska A, Mors O, Staunstrup NH, Børglum AD, Qvist P (2020) Neuropsin in mental healt. J Physiol Sci 70: 26

Carpenter AE, Jones TR, Lamprecht MR, Clarke C, Kang IH, Friman O, Guertin DA, Chang JH, Lindquist RA, Moffat J et al (2006) CellProfiler: image analysis software for identifying and quantifying cell phenotypes. Genome Biol 7: R100

Choudhury R, Singh S, Arumugam S, Roguev A, Stewart AF (2019) The Set1 complex is dimeric and acts with Jhd2 demethylation to convey symmetrical H3K4 trimethylation. Genes \& development 33: 550-564

Collins BE, Sweatt JD, Greer CB (2019) Broad domains of histone 3 lysine 4 trimethylation are associated with transcriptional activation in CA1 neurons of the hippocampus during memory formation. Neurobiol Learn Mem 5: 149-157

Deng C, Li Y, Liang S, Cui K, Salz T, Yang H, Tang Z, Gallagher PG, Qiu Y, Roeder R et al (2013) USF1 and hSET1A mediated epigenetic modifications regulate lineage differentiation and HoxB4 transcription. PLoS Genet 9: e1003524

Dreijerink KM, Mulder KW, Winkler GS, Hoppener JW, Lips CJ, Timmers HT (2006) Menin links estrogen receptor activation to histone H3K4 trimethylation. Cancer Research 66: 4929-4935

Eisenberg E, Levanon EY (2013) Human housekeeping genes, revisited. Trends in genetics 29: 569574

Feng J, Liu T, Qin B, Zhang Y, Liu XS (2012) Identifying ChIP-seq enrichment using MACS. Nat Protoc 7: 1728-1740

Fischer A (2014) Targeting histone-modifications in Alzheimer's disease. What is the evidence that this is a promising therapeutic avenue? Neuropsychopharmacology 80: 95-012

Gabriele M, Lopez Tobon A, D'Agostino G, Testa G (2018) The chromatin basis of neurodevelopmental disorders: Rethinking dysfunction along the molecular and temporal axes. Prog Neuropsychopharmacol Biol Psychiatry 84: 306-327

Gjoneska E, Pfenning AR, Mathys H, Quon G, Kundaje A, Tsai LH, Kellis M (2015) Conserved epigenomic signals in mice and humans reveal immune basis of Alzheimer's disease. Nature 518: 365-369

Gupta S, Kim SY, Artis S, Molfese DL, Schumacher A, Sweatt JD, Paylor RE, Lubin FD (2010) Histone methylation regulates memory formation. J Neurosci 30: 3589-3599

Halder R, Hennion M, Vidal RO, Shomroni O, Rahman RU, Rajput A, Centeno TP, van Bebber F, Capece V, Vizcaino JC et al (2016) DNA methylation changes in plasticity genes accompany the formation and maintenance of memory. Nat Neurosci 19: 102-110

Heinz S, Benner C, Spann N, Bertolino E, Lin YC, Laslo P, Cheng JX, Murre C, Singh H, Glass CK (2010) Simple combinations of lineage-determining transcription factors prime cis-regulatory elements required for macrophage and B cell identities. Mol Cell 38: 576-589

Hiraide T, Nakashima M, Yamoto K, Fukuda T, Kato M, Ikeda H, Sugie Y, Aoto K, Kaname T, Nakabayashi K et al (2018) De novo variants in SETD1B are associated with intellectual disability, epilepsy and autism. Hum Genet 137: 95-104

Hughes C, M, Rozenblatt-Rosenm O, Milnem T A, Copelandm T D, Levinemm S.S, Lee JC, Hayes DN, Shanmugam KS, Bhattacharjee A, Biondi CA et al (2004) Menin associates with a trithorax family histone methyltransferase complex and with the hoxc8 locus. Mol Cell: 4

Hwang J-Y, Zukin RS (2018) REST, a master transcriptional regulator in neurodegenerative disease. Current Opinion in Neurobiology 48: 193-200

Illouz T, Madar R, Louzon Y, Griffioen KJ, Okun E (2016) Unraveling cognitive traits using the Morris water maze unbiased strategy classification (MUST-C) algorithm. Brain Behav Immun 52: 132-144

Islam MR, Lbik D, Sakib MS, Hofmann M, Berulava T, Jiménez Mausbach M, Cha J, Goldberg M, Vakhtang E, Schiffmann C et al (2021) Epigenetic gene expression links heart failure to memory impairment. Embo Mol Med 13: Epub ahed of print 
bioRxiv preprint doi: https://doi.org/10.1101/2021.08.02.454636; this version posted August 2, 2021. The copyright holder for this preprint (which was not certified by peer review) is the author/funder, who has granted bioRxiv a license to display the preprint in perpetuity. It is made available under aCC-BY-ND 4.0 International license.

758 Kerimoglu C, Agis-Balboa RC, Kranz A, Stilling R, Bahari-Javan S, Benito-Garagorri E, Halder R,

759 Burkhardt S, Stewart AF, Fischer A (2013) Histone-methyltransferase mll2 (kmt2b) is required for memory formation in mice. J Neurosci 33: 3452-3464

Kerimoglu C, Sakib MS, Jain G, Benito E, Burkhardt S, Capece V, Kaurani L, Halder R, Agís-Balboa RC, Stilling R et al (2017) KMT2A and KMT2B Mediate Memory Function by Affecting Distinct Genomic Regions. Cell reports 20: 538-548

Kleefstra T, Schenck A, Kramer JM, van Bokhoven H (2014) The genetics of cognitive epigenetics. Neuropharmacology 80: 83-94

Kranz A, Anastassiadis KT (2020) The role of SETD1A and SETD1B in development and disease. Biochim Biophys Acta Gene Regul Mech 1863: 10.1016/j.bbagrm.2020.194578

Kuczera T, Stilling RM, Hsia HE, Bahari-Javan S, Irniger S, Nasmyth K, Sananbenesi F, Fischer A (2010) The anaphase promoting complex is required for memory function in mice. Learn Mem 18: 49-57

771 Labonne JD, Lee KH, Iwase S, Kong IK, Diamond MP, Layman LC, Kim CH, Kim HG (2016) An atypical 12q24.31 microdeletion implicates six genes including a histone demethylase KDM2B and a histone methyltransferase SETD1B in syndromic intellectual disability. Hum Genet 135: 757-771 Larizza L, Finelli P (2019) Developmental disorders with intellectual disability driven by chromatin dysregulation: Clinical overlaps and molecular mechanisms. Clin Genet 95: 231-240

Lee JH, Skalnik DG (2008) Wdr82 is a C-terminal domain-binding protein that recruits the Setd1A Histone H3-Lys4 methyltransferase complex to transcription start sites of transcribed human genes. Mol Cell Biol 28: 609-618

Lee S, Lee DK, Dou Y, Lee J, Lee B, Kwak E, Kong YY, Lee SK, Roeder RG, Lee JW (2006) Coactivator as a target gene specificity determinant for histone $\mathrm{H} 3$ lysine 4 methyltransferases. Proc Natl Acad Sci U S A 103: 15392-15397

Li H, Handsaker B, Wysoker A, Fennell T, Ruan J, Homer N, Marth G, Abecasis G, Durbin R (2009) The Sequence Alignment/Map format and SAMtools. Bioinformatics 25: 2078-2079

Lin H, Min Z, Tao Q (2016) The MLL/Setd1b methyltransferase is required for the Spemann's organizer gene activation in Xenopus. Mech Dev 142

Love MI, Huber W, Anders S (2014) Moderated estimation of fold change and dispersion for RNAseq data with DESeq2. Genome Biol 15: 550

Ma M, Zhang Y, Weng M, Hu Y, Xuan Y, Hu Y, Lv K (2018) lncRNA GCAWKR Promotes Gastric Cancer Development by Scaffolding the Chromatin Modification Factors WDR5 and KAT2A. Mol Ther 26: 2658-2668.

Marangi G, Orteschi D, Milano V, Mancano G, Zollino M (2013) Interstitial deletion of 3p22.3p22.2 encompassing ARPP21 and CLASP2 is a potential pathogenic factor for a syndromic form of intellectual disability: a co-morbidity model with additional copy number variations in a large family. Am J Med Genet A 161: 2890-2893

Minichiello L, Korte M, Wolfer D, Kühn R, Unsicker K, Cestari V, Rossi-Arnaud C, Lipp HP, Bonhoeffer T, Klein R (1999) Essential role for TrkB receptors in hippocampus-mediated learning. Neuron 24: 401-414

Mishra BP, Zaffuto KM, Artinger EL, Org T, Mikkola HK, Cheng C, Djabali M, Ernst P (2014) The histone methyltransferase activity of MLL1 is dispensable for hematopoiesis and leukemogenesis. Cell Rep 7: 1239-1247

Mukai J, Cannavò E, Crabtree GW, Sun Z, Diamantopoulou A, Thakur P, Chang CY, Cai Y, Lomvardas S, Takata A et al (2019). Recapitulation and Reversal of Schizophrenia-Related Phenotypes in Setd1a-Deficient Mice. Neuron. Neuron 104: 471-487

Nestler EJ, Peña CJ, Kundakovic M, Mitchell A, Akbarian S (2015) Epigenetic Basis of Mental Illness. Neuroscientist 8

Nicol JW, Helt GA, Blanchard SG, Jr., Raja A, Loraine AE (2009) The Integrated Genome Browser: free software for distribution and exploration of genome-scale datasets. Bioinformatics 25: 2730-2731 Park S KG, Kwon SH, Lee JS. Broad domains of histone H3 lysine 4 trimethylation in transcriptional 809 regulation and disease. FEBS J. 2020 Jul;287(14):2891-2902 (2020) Broad domains of histone H3 810 lysine 4 trimethylation in transcriptional regulation and disease. FEBS J 287: 2891-2902

811 Rao RC DYHictKMfomNRCJ- (2015) Hijacked in cancer: the KMT2 (MLL) family of 812 methyltransferases. Nat Rev Cancer 15: 334-346 
bioRxiv preprint doi: https://doi.org/10.1101/2021.08.02.454636; this version posted August 2, 2021. The copyright holder for this preprint (which was not certified by peer review) is the author/funder, who has granted bioRxiv a license to display the preprint in perpetuity. It is made available under aCC-BY-ND 4.0 International license.

813 Redrobe JP, Dumont Y, Herzog H, Quirion R (2004) Characterization of neuropeptide Y, Y(2)

814 receptor knockout mice in two animal models of learning and memory processing. J Mol Neurosci 22:

815 159-166

816 Rehfeld F, Maticzka D, Grosser S, Knauff P, Eravci M, Vida I, Backofen R, Wulczyn FG (2018) The

817 RNA-binding protein ARPP21 controls dendritic branching by functionally opposing the miRNA it

818 hosts. Nat Commun 9: 1235-1241

819 Ross-Innes CS, Stark R, Teschendorff AE, Holmes KA, Ali HR, Dunning MJ, Brown GD, Gojis O,

820 Ellis IO, Green AR et al (2012) Differential oestrogen receptor binding is associated with clinical outcome in breast cancer. Nature 481: 389-393

Roston A, Evans D, Gill H, McKinnon M, Isidor B, Cogné B, Mwenifumbo J, van Karnebeek C, An J, Jones SJM et al (2020) SETD1B-associated neurodevelopmental disorder. J Med Genet 58: 196204

825 Scacheri PC, Davis S, Odom DT, Crawford GE, Perkins S, Halawi MJ, Agarwal SK, Marx SJ, 826 Spiegel AM, Meltzer PS et al (2006) Genome-wide analysis of menin binding provides insights into MEN1 tumorigenesis. PLoS Genet 2: e51

Schmidt K, Zhang Q, Tasdogan A, Petzold A, Dahl A, Arneth BM, Slany R, Fehling HJ, Kranz A, Stewart AF et al (2018) The histone 3 lysine 4 methyltransferase Setd1b is essential for hematopoietic stem and progenitor cell homeostasis in mice. eLife 7

Shen L, Shao N, Liu X, Nestler E (2014) ngs.plot: Quick mining and visualization of next-generation sequencing data by integrating genomic databases. BMC Genomics 15: 284

Shilatifard A (2012) The COMPASS family of histone H3K4 methylases: mechanisms of regulation in development and disease pathogenesis. Annual reviews of Biochemistry 81: 65-95

Shinsky SA, Monteith KE, Viggiano S, Cosgrove MS (2015) Biochemical reconstitution and phylogenetic comparison of human SET1 family core complexes involved in histone methylation. $J$ Biol Chem 290: 6361-6375

838 Shulha HP, Cheung I, Whittle C, Wang J, Virgil D, Lin CL, Guo Y, Lessard A, Akbarian S, Weng Z 839 (2012) Epigenetic signatures of autism: trimethylated H3K4 landscapes in prefrontal neurons. Arch $840 \quad$ Gen Psychiatry 69: 314-324

841 Soares LM, He PC, Chun Y, Suh H, Kim T, Buratowski S (2017) Determinants of Histone H3K4 Methylation Patterns. Molecular cell. Molecular cell 68: 773-785

Stilling R, Rönicke R, Benito-Garagorri E, Urbanke H, Capece V, Burckhard S, Bahari-Javan S, Barth J, Sananbenesi F, Schütz AL et al (2014) K-Lysine acetlytransferase 2A regualtes a hippocampal gene-expression network linked to memory formation. EMBO J 33: 1912-1927

Sweatt JD (2001) The neuronal MAP kinase cascade: a biochemical signal integration system subserving synaptic plasticity and memory. J Neurochem 76: 1-10

Sze CC, Ozakr PA, Cao K, Ugarenko M, Das S, Wang L, Marshall SA, Rendleman EJ, Ryan CA, Zha $\mathrm{D}$ et al (2020) Coordinated regulation of cellular identity-associated H3K4me3 breadth by the COMPASS family. Science Advances 6

851 Tahiliani M, Mei P, Fang R, Leonor T, Rutenberg M, Shimizu F, Li J, Rao A, Shi Y (2007) The 852 histone H3K4 demethylase SMCX links REST target genes to X-linked mental retardation. Nature 853 447: 601-605

854 Tamura H, Ishikawa Y, Hino N, Maeda M, Yoshida S, Kaku S, Shiosaka S (2006) Neuropsin is essential for early processes of memory acquisition and Schaffer collateral long-term potentiation in adult mouse hippocampus in vivo. $J$ Physiol 570: 541-551

Tsilibary E, Tzinia A, Radenovic L, Stamenkovic V, Lebitko T, Mucha M, Pawlak R, Frischknecht R, Kaczmarek L (2014) Neural ECM proteases in learning and synaptic plasticity. Prog Brain Res 214: $135-157$

861

862

Vallianatos CN, Raines B, Porter RS, Bonefas KM, Wu MC, Garay PM, Collette KM, Seo YA, Dou $\mathrm{Y}$, Keegan CE et al (2020) Mutually suppressive roles of KMT2A and KDM5C in behaviour, neuronal structure, and histone H3K4 methylation. Commun Biol 1: doi: 10.1038/s42003-4202041001-42006

864 Wang Z, Zang C, Cui K, Schones DE, Barski A, Peng W, Zhao K (2009) Genome-wide mapping of 
868 Wu M, Wang PF, Lee JS, Martin-Brown S, Florens L, Washburn M, Shilatifard A (2008) Molecular 869 regulation of H3K4 trimethylation by Wdr82, a component of human Set1/COMPASS. Mol Cell Biol 870 28: 7337-7344

871 Yokoyama A, Wang Z, Wysocka J, Sanyal M, Aufiero DJ, Kitabayashi I, Herr W, Cleary ML (2004) 872 Leukemia proto-oncoprotein MLL forms a SET1-like histone methyltransferase complex with menin 873 to regulate Hox gene expression. Molecular and cellular biology. Molecular and cellular biology 24: $874 \quad 5639-5649$

875 Yu G, Wang LG, He QY (2015) ChIPseeker: an R/Bioconductor package for ChIP peak annotation, 876 comparison and visualization. Bioinformatics 31: 2382-2383

877

\section{Acknowledgments}

879 This work was supported by the following third party funds to AF: The ERC consolidator grant 880 DEPICODE (648898), the BMBF projects ENERGI (01GQ1421A) and Intergrament (01ZX1314D), 881 and funds from the German Center for Neurodegenerative Diseases FS was supported by the DFG 882 grant SA1005/2-1and funds from the DZNE. AM is a student of the International Max Planck 883 Research School (IMPRS) for Genome Science. SS \& RI are students of the IMPRS for 884 Neuroscience.

Author contributions

887 AM initiated the project as part of her $\mathrm{PhD}$ thesis, performed behavior experiments, performed and 888 analyzed immunohistochemistry and analyzed mutant mice; SS generated cell-type specific 889 ChIP/RNA-seq and single nucleus RNA-seq data and contributed to the analysis of cell type specific 890 RNA-seq, CK analyzed and interpreted ChIP-seq and RNA-seq data and supervised all bioinformatic 891 data analysis, DMF analyzed single nucleus RNA-seq data, LK, XX \& EMZ helped with the 892 generation of single nucleus RNA-seq; SS, JPD \& GE performed and supervised RNAscope 893 experiments, AK \& FAS provided material and analyzed data, AM, SS, CK and AF designed 894 experiments and generated figures. $\mathrm{CK}$ and $\mathrm{AF}$ wrote the paper.

896 Competing interests

897 The authors declare no competing interests 
900

901

902

903

904

905

906

907

908

909

910

911

912

913

914

915

916

917

918

919

920

921

922

923

924

925

926

927

928

929

930

931

932

933

934

935

936

\section{Figure legends}

Figure 1. Setd1b is required for hippocampus-dependent memory. A. qPCR analysis shows loss of Setdlb in forebrain regions while levels in the cerebellum are not affected (CA: Control, $\mathrm{n}=6$; $\mathrm{cKO}, \mathrm{n}=6$. DG: Control, $\mathrm{n}=6$; $\mathrm{cKO}, \mathrm{n}=6$. Cortex: Control, $\mathrm{n}=7 ; \mathrm{cKO}, \mathrm{n}=7$. Cerebellum: Control, $\mathrm{n}=4 ; \mathrm{cKO}, \mathrm{n}=4){ }^{*} p$-value $<0.05$ (Student t-test). B. Immunoblot analysis shows loss of SETD1B protein in the hippocampus of Setd1b cKO mice (Control, $\mathrm{n}=4 ; \mathrm{cKO}, \mathrm{n}=4$ ). ** $p$-value $<0.01$ (Student t-test). C. Immunohistochemical staining (upper level) for marker proteins of neuronal integrity and quantification (lower panel) show no difference in control and Setd1b cKO mice (NeuN: Control, $\mathrm{n}=6$; $\mathrm{cKO}, \mathrm{n}=6$; Student t-test $p$-value $=0.57$. MAP2: Control, $\mathrm{n}=4 ; \mathrm{cKO}, \mathrm{n}=4$; Student t-test $p$-value $=0.72$. Iba1: Control, $\mathrm{n}=5 ; \mathrm{cKO}, \mathrm{n}=5$; Student t-test $p$-value $=0.8$. Gfap: Control, $\mathrm{n}=5$; cKO, $\mathrm{n}=5$; Student t-test $p$-value $=0.09$.). Scale bar: $100 \mu \mathrm{m}$. D. Average speed (left panel) and percent time spent in the center (right panel) during exposure to the open field test was similar in control and Setd $1 b$ cKO mice (Average speed: Control, $\mathrm{n}=15 ; \mathrm{cKO}, \mathrm{n}=15$; Student t-test $p$-value $=0.075$. Time spent in center: Control, $\mathrm{n}=15 ; \mathrm{cKO}, \mathrm{n}=15$; Student t-test $p$-value $=0.96) . \mathbf{E}$. Short term memory was not different between control and Setd $1 b$ cKO mice as indicated by similar percent of alternations in the $\mathrm{Y}$-maze test (Control, $\mathrm{n}=15 ; \mathrm{cKO}, \mathrm{n}=15$; Student $\mathrm{t}$-test $p$-value $=0.3$ ). F. Depressive-like behavior was measured in the Porsolt forced swim test. There was no significant difference in the $\%$ time spent immobile between groups (Control, $\mathrm{n}=8 ; \mathrm{cKO}, \mathrm{n}=8$; Student t-test $p$ value $=0.5)$. G. Escape latency during water maze training indicated severe learning impairment in Setdlb cKO mice (Control: $\mathrm{n}=15$, cKO: $\mathrm{n}=15$. Repeated measures ANOVA, genotype effect: $\mathrm{F}$ $(1,28)=82.34, * * * * p$-value $<0.0001)$. H. Plots showing the specific search strategies during water maze training. Note the failure of Setdlb cKO mice to adopt hippocampus-dependent search strategies. I. The cognitive score calculated on the basis of the hippocampal search strategies reflects severe memory impairment in Setd1b cKO mice (Student t-test: *** p-value $<0.001$ ).

Figure 2. Setd1b controls H3K4 methylation and H3K4me3 peak width. A. Experimental scheme showing our approach to perform cell type specific ChIP-Seq and RNA-Seq. For ChIP-Seq we employed $\mathrm{n}=4$ for control and $\mathrm{n}=4$ for Setd $1 b$ cKO. B. Left panel: Heat map showing genomic regions with significantly differing $\mathrm{H} 3 \mathrm{~K} 4 \mathrm{me} 3$ sites at the close vicinity of TSS $(+/-2 \mathrm{~kb})$ in Setdlb cKO mice and the overall genomic locations of altered H3K4me3 levels. Right panel shows the same analysis for H3K4me1 (FDR $<0.05 \&$ fold change $\mid>1.5$ ). C. Bar plot showing the number of TSS regions (+/- 2kb) with decreased and increased H3K4me3 and H3K4me1 in Setd1b cKO mice (FDR < $0.05 \&$ fold change $>1.5$ ). D. Profile plot showing H3K4me3 across all genes with significantly reduced H3K4me3 in Setd1b cKO mice. Left panel shows a bar chart indicating that reduced H3K4me3 in Setd1b cKO mice is mainly occurring downstream of the TSS (*** Student t-test $p$ value $<0.001)$. E. Profile plots showing the distribution of H3K4me3 and H3K4me1 at the close 
937 vicinity of TSS of genes that show significantly reduced H3K4me3 and increased H3K4me1 in

938 Setdlb cKO mice. Bar graphs on the right show corresponding quantification (Student t-test: ** $p$ -

939 value $<0.01, * * * * p$-value $<0.0001)$. F. Profile plots showing the distribution of H3K4me3 and

$940 \mathrm{H} 3 \mathrm{~K} 4 \mathrm{me} 1$ at the TSS of genes that show both reduced H3K4me3 and H3K4me1 in Setd 1b cKO mice.

941 Bar graphs on the left show corresponding quantification (Student t-test: * $p$-value $<0.05, * * * p$ -

942 value $<0.0001$ ). G. Heatmap (left panel) showing basal state H3K4me3 width around TSS of genes

943 characterized by decreased H3K4me3 in combination with either increased or decreased H3K4me1 in

944 Setdlb cKO mice. Right panel: Quantification of the basal state H3K4me3 width around TSS of genes

945 with decreased H3K4me3 in combination with either increased (472 peaks), decreased (401 peaks) or

946 not altered H3K4me1 (1051 peaks) in Setdlb cKO mice (One-way ANOVA: $p$-value $<0.0001$. Post-

947 hoc multiple comparisons, Tukey's test: increased H3K4me1 vs no change H3K4me1, **** $p$-value $<$

9480.0001 ; increased H3K4me1 vs decreased H3K4me1, **** $p$-value $<0.0001$; no change H3K4me1 vs

949 decreased H3K4me1, $\S \S \S p$-value $<0.0001)$. H. Violin plot showing the basal expression level for

950 the 3 categories of genes that display decreased H3K4me3 in Setd1b cKO mice, now analyzed in wild

951 type mice (increased H3K4me1: 456 genes, decreased H3K4me1: 382 genes, not altered H3K4me1:

952993 genes). The basal expression level is highest for genes with decreased H3K4me3 in combination

953 with increased H3K4me1 that are characterized by broad H3K4me3 peaks (One-way ANOVA: $p$ -

954 value $<0.0001$. Post-hoc multiple comparisons, Tukey's test: increased H3K4me1 vs no change

955 H3K4me1, **** $p$-value $<0.0001$; increased H3K4me1 vs decreased H3K4me1, **** $p$-value $<$

956 0.0001; no change H3K4me1 vs decreased H3K4me1, $p$-value $=0.6967)$. Please note that the number

957 of genes is smaller than the number of peaks in $(\mathrm{G})$ because in some cases there are more than one

958 peaks around TSS of the same gene. I. Heat map showing functional pathways for the 3 categories of

959 genes affected by reduced H3K4me3 in Setd $1 b$ cKO mice. Error bars indicate SEM.

960

961 Figure 3. Hippocampal Setd1b controls highly expressed learning and memory genes

962 characterized by a broad H3K4me3 peak. A. nucRNA-seq experiment. Volcano plot showing

963 genes differentially expressed in hippocampal CA neurons of Setd1b cKO mice. $\mathrm{n}=3$ /group. B.

964 Profile plots showing H3K4me3 and H3K4me1 at the TSS of genes downregulated in Setd1b cKO

965 mice. Bar plots (right panel) show quantification (Student t-test: $* p$-value $<0.05, * * * p$-value $<$

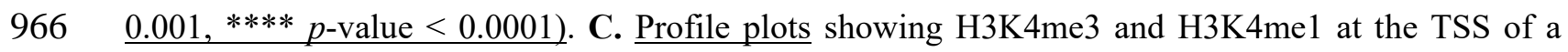

967 random set of genes (equal in number to downregulated genes) that were not altered in Setd $1 b$ cKO

968 mice. Bar plot (right panel) shows quantifications. D. Arpp21 (CAMP Regulated Phosphoprotein 21)

969 was selected as a representative gene downregulated in hippocampal neurons of Setd $1 b$ cKO mice to

970 illustrate changes in the analyzed histone modifications. Please note that the H3K4me3 peak width is

971 substantially shrinking in Setdlb cKO mice. At the same time there is an obvious increase of

972 H3K4me1 at the TSS of Arpp21 in Setd1b cKO mice. E. Left panel: H3K4me3 peaks are

973 significantly broader in genes that are downregulated in Setdlb cKO mice, when compared to a 
random set of genes of equal number that were unaffected. Right panel: Genes downregulated in Setdlb cKO mice are characterized by higher baseline expression when compared to a random set of genes of equal number that were unaffected (Student t-test: **** $p$-value $<0.0001$ ). F. Heat map showing functional pathways affected by genes downregulated in Sed1b cKO mice. Error bars indicate SEM.

Figure 4. Comparative analysis of the hippocampal epigenome and transcriptome in Setd1b, $K m \boldsymbol{t} 2 \boldsymbol{a}$ and $K \boldsymbol{K} \boldsymbol{t} \mathbf{2 b}$ cKO mice. A. Bar chart showing the number of TSS regions $(+/-2 \mathrm{~kb})$ that exhibit significantly altered $\mathrm{H} 3 \mathrm{~K} 4 \mathrm{me} 3(\mathrm{Kmt} 2 \mathrm{a}$ : control, $\mathrm{n}=5$; $\mathrm{cKO}, \mathrm{n}=3$. Kmt2b: control, $\mathrm{n}=6$; cKO, $\mathrm{n}=$ 5. Setd $1 \mathrm{~b}$ : control, $\mathrm{n}=4 ; \mathrm{cKO}, \mathrm{n}=4)$. B. Bar chart showing the number of TSS regions $(+/-2 \mathrm{~kb})$ that exhibit significantly altered H3K4me1. C. Venn diagram comparing the TSS regions with significantly decreased $\mathrm{H} 3 \mathrm{~K} 4 \mathrm{me} 3$ in the 3 respective cKO mice. D. Bar chart showing the number of differentially expressed genes from bulk RNA-seq in each of the $3 \mathrm{KMT}$ cKO mice. Kmt2a: control, $\mathrm{n}$ = 5; $\mathrm{cKO}, \mathrm{n}=6 . \mathrm{Kmt} 2 \mathrm{~b}$ : control, $\mathrm{n}=8 ; \mathrm{cKO}, \mathrm{n}=11$. Setd1b: control, $\mathrm{n}=6$; $\mathrm{cKO}, \mathrm{n}=6$ ). E. Venn diagram comparing the significantly downregulated genes amongst the 3 respective cKO mice. $\mathbf{F}$. Downregulated genes with concomitantly decreased $\mathrm{H} 3 \mathrm{~K} 4 \mathrm{me} 3$ in each of the $3 \mathrm{KMT}$ cKO mice were tested for the overlap to the 836 neuron-specific genes we had defined for the hippocampal CA region (See Fig EV5). Only for Setd1b cKO mice a highly significant odds ratio (Fisher's exact test) was observed (65 out of 161), while there was no significant association amongst neuron-specific genes and the genes affected in $K m t 2 a \mathrm{cKO}(9$ out of 112) or $K m t 2 b \mathrm{cKO}(20$ out of 379) mice (see also Fig EV11 for all downregulated genes in each of the KMT cKOs). G. Left panel: Bar graphs showing H3K4me3 binding around the TSS $(+/-2 \mathrm{~kb})$ of downregulated genes in either of the $3 \mathrm{KMT}$ cKO mice (Two-way ANOVA: * $p$-value $<0.05, * * * p$-value $<0.001$ ). Right panel depicts H3K4me1 binding at the same TSS regions (Two-way ANOVA: **** $p$-value $<0.0001$ ). Note that only in Setdlb cKO mice decreased H3K4me3 is accompanied by significantly increased H3K4me1. H. Genes exhibiting decreased H3K4me3 and reduced expression in Kmt2a, Kmt $2 b$ or Setd1b cKO mice were analyzed for H3K4me3 peak width around the TSS under basal conditions. Genes affected in Setdlb cKO mice displayed significantly broader H3K4me3 peak width when compared to genes 1002 affected in $K m t 2 a$ or $K m t 2 b$ cKO mice. H3K4me3 peak widths at random sets of unchanged genes of

1003 equal size are shown for comparison. Comparisons between genes with decreased H3K4me3 and 1004 expression in the KMT cKOs: One-way ANOVA, $p$-value $<0.0001$. Post-hoc multiple comparisons, 1005 Tukey's test: Setdlb cKO vs Kmt2a cKO, **** $p$-value $<0.0001 ;$ Setd $1 b$ cKO vs Kmt $2 b$ cKO, **** $1006 p$-value $<0.0001 ; K m t 2 a$ cKO vs Kmt $2 b$ cKO, **** $p$-value $<0.0001$. Comparisons between "down" 1007 and "unchanged" sets in each KMT cKO: Setd $1 b$ cKO, t-test $p$-value $<0.0001 ; K m t 2 a$ cKO, Student $1008 \quad$ t-test $p$-value $<0.0001 ; K m t 2 b \mathrm{cKO}$, Student t-test $p$-value $<0.0001$. I. Violin plots showing average 1009 basal expression of downregulated genes with decreased H3K4me3 levels at the TSS in Kmt2a, $1010 K m t 2 b$ or Setd $1 b$ cKO mice. Genes affected in Setdlb KO mice are expressed at significantly higher 
1011 levels under basal conditions when compared to genes affected in Kmt $2 a \mathrm{cKO}$ or Kmt $2 b \mathrm{cKO}$ mice.

1012 Comparisons between genes with decreased H3K4me3 and expression in the KMT cKOs: One-way 1013 ANOVA, $p$-value $<0.0001$. Post-hoc multiple comparisons, Tukey's test: Setdlb cKO vs Kmt $2 a$

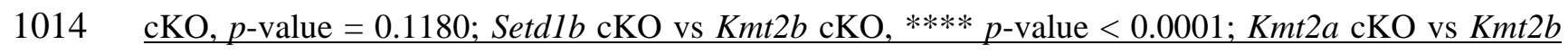

$1015 \mathrm{cKO}, * * * * p$-value $<0.0001$. Comparisons between "down" and "unchanged" sets in each KMT 1016 cKO: Setdlb cKO, t-test $p$-value $<0.01 ; K m t 2 a$ cKO, t-test $p$-value $=0.3967 ; K m t 2 b$ cKO, t-test $p$ 1017 value $<0.0001$. J. Heat map showing functional pathways of genes affected in Kmt2a, Kmt2b or 1018 Setd $1 b$ cKO mice. Note that genes affected by loss of Setd $1 \mathrm{~b}$ specifically represent pathways linked to 1019 excitatory neuronal function. Error bars indicate SEM.

Expanded View Figure Legends

1024 Expanded view Fig 1: Behavioral analysis of mice expressing CamKII-driven Cre recombinase.

A. Transgenic mice expressing Cre under control of the CamKII promoter were subjected to behavior testing $(\mathrm{n}=8, \mathrm{Cre}+)$ comparing them to wild type mice from the same breeding colony that did not express Cre ( $\mathrm{n}=8$; Cre-). No difference was observed in body weight. B-C. The distance traveled in the open field test $(\mathrm{B})$ and the time spent in the center of the arena $(\mathrm{C})$ were similar amongst groups. D. No difference in the swimming speed was observed amongst groups when subjected to the water maze test. E. Escape latency during water maze training was similar in Cre- and Cre+ mice. F-G. During the probe test performed after 10 training days, Cre- and Cre + mice showed similar performance when time spent in the target quadrant $(F)$ and the number of platform crossings $(G)$ were analyzed. Error bars indicate SEM.

\section{Expanded view Fig. 2. Analysis of memory recall cannot be interpreted in Setd1b cKO mice.}

A. $24 \mathrm{~h}$ after the completion of the 10 day-training procedure in the water maze paradigm (See Fig 1G) mice were subjected to a probe test. The performance in the probe test, as measured by the time spent in the target quadrant (TQ), is impaired in Setdlb cKO mice (Control: $\mathrm{n}=15$, cKO: $\mathrm{n}=15$. **** Student t-test $<0.0001)$. These results have to be interpreted with care, however, since faulty

1040 interpretation about memory recall is possible in this experiment since the Setdlb cKO mice not even

1041 being able to form the memory during the training (See Fig 1G, H). It is moreover important to note 1042 that Setd $1 b$ cKO mice spent even less time in tQ than would be predicted by chance alone. To address 1043 the issue we analyzed the swim speed during the entire experiment (B) and noticed that the swim 1044 speed was similar in control and Setdlb cKO mice across the first 5 days of training. There was 1045 however a trend for reduced swim speed in Setdlb cKO mice from training day 6 to 10. Although we 1046 did not detect significant differences in the swim speed when we analyzed the average values across 1047 all training days, a more detailed analysis revealed that swim speed was significantly impaired in 
Setd1b cKO mice at training day $10(*$ Student t-test $=0.016)$ and also during the probe test $(* *$ Student t-test $=0.001)$. These data may help to explain why the Setdlb cKO mice appear to avoid the target quadrant during the one trial $60 \mathrm{sec}$ probe test session. The training session consists of a sequence of $4 \times 60 \mathrm{sec}$ sessions and mice are always placed into the pool from 4 different locations.

1052 During the probe test, that consists of a one trial $60 \mathrm{sec}$ session, animals are always placed in the quadrant opposite to the target quadrant, i.e., the quadrant that is the farthest aways from the target quadrant. While the reason for the reduced swim speed after 9 days of training is unclear, at present these data do not affect the conclusion that Setdlb cKO mice exhibit impaired learning ability. Error bars indicate SEM.

Expanded view Fig. 3: A. Principal component analysis (PCA) plot from H3K4me3 ChIP-Seq experiment. B. PCA plot from H3K4me1 ChIP-Seq experiment. C. PCA plot from H3K9ac ChIP-Seq experiment. D. PCA plot from H3K27ac ChIP-Seq experiment. E. PCA plot from RNA-Seq experiment performed from FACS-sorted neuronal ( $\mathrm{NeuN+}$ ) nuclei. F. PCA plot from RNA-Seq experiment performed from bulk CA tissue.

Expanded view Fig. 4: Decreased H3K9ac and H3K27ac in Setd1b cKO mice. A. Left panel: Heat map showing genomic regions with differentially bound $\mathrm{H} 3 \mathrm{~K} 9 \mathrm{ac}$ sites in the close vicinity of TSS $\underline{(+/-2 \mathrm{~kb})}$ in neuronal nuclei from Setdlb cKO mice and the overall genomic locations of altered H3K9ac levels (Control: $\mathrm{n}=4$; Setdlb cKO: $\mathrm{n}=3$ ). Right panel shows the same analysis for H3K27ac (Control: $\mathrm{n}=3$; Setd1b cKO: $\mathrm{n}=4)$. B. Bar chart showing the number of genes with significantly decreased and increased H3K9ac and H3K27ac marks at the TSS region $(+/-2 \mathrm{~kb})$. Data for $\mathrm{H} 3 \mathrm{~K} 4 \mathrm{me} 3$ and $\mathrm{H} 3 \mathrm{~K} 4 \mathrm{me} 1$ are shown for comparison. As expected, the most affected histone mark is H3K4me3. C. Venn diagram showing that most of the sites exhibiting decreased H3K9ac at the TSS also exhibit reduced H3K4me3, while this is not the case for H3K27ac. TSS, transcription start site.

Expanded view Fig. 5: Sorting neuronal and non-neuronal nuclei for RNA-Seq analysis. Nuclei from the hippocampal CA region were subjected to FANS as depicted in Fig 2A. A. Representative images showing nuclei that were sorted using the neuronal marker NeuN. Note that no NeuN positive 1078 nuclei are detected in the NeuN (-) fraction confirming the purity of the approach. Scale bar: 50 $\mu \mathrm{m} \mathbf{B}$. 1079 Gating strategy for NeuN (+) and NeuN (-) nuclei sorting. C. RNA-sequencing (n=2/group) was 1080 performed from $\mathrm{NeuN}(+)$ and $\mathrm{NeuN}(-)$ nuclei and a differential expression analysis was performed. 1081 Heat map shows 836 genes specifically enriched in NeuN (+) nuclei when compared to NeuN (-) 1082 nuclei. The criteria to select those genes were: adjusted $p$-value $<0.01$, basemean $>150$, fold change 1083 > 5. D. GO-term analysis showing that the top 10 enriched biological processes and molecular 1084 functions for the 836 genes enriched in NeuN (+) nuclei all represent specific neuronal processes. E. 
Normalized expression values obtained from the RNA-seq experiment showing the expression of selected genes known to be enriched in neurons. F. Normalized expression values of genes that are known to be enriched in non-neuronal cells including glia cells. Error bars indicate SEM.

1089 Expanded view Fig. 6. Confirmation of RNA-seq results via qPCR. Randomly selected genes that 1090 were either significantly up- (5 genes) or downregulated (5 genes) in the RNA-seq dataset comparing control vs Setdl $1 b$ cKO mice were tested via qPCR for validation. The graph shows the corresponding $\log 2$ (fold changes) in each experiment. The RNA-seq and qPCR results show highly significant correlation. and H3K27ac levels. A. Profile plots showing H3K9ac and H3K27ac levels at genes with decreased H3K4me3 in Setd1b cKO. B. Profile plots showing H3K9ac and H3K27ac levels at downregulated (upper panels) and an equally sized random set of unchanged genes (lower panels) in Setdlb cKO. Bar graphs on the right of each profile plot show quantifications of the enrichment of the histone mark at corresponding genomic regions away from TSS (Student t-test: $* p$-value $<0.05$, $* * p$-value $<0.01$, *** $p$-value $<0.001)$.

Expanded view Fig. 8: Genome browser views showing the 4 analyzed four histone modifications and the gene expression pattern for the $N p y 2 r$ and $K l k 8$ genes that were previously shown to be involved in synaptic plasticity and learning \& memory.

Expanded view Fig. 9: Comparison of gene expression changes in Setd1b cKO mice detected downregulated in Setdlb cKO mice detected via RNA-seq from neuronal nuclei or bulk hippocampal CA tissue. Importantly, the majority of the downregulated genes detected in bulk tissue RNA-seq are also detected in RNA-seq from neuronal nuclei (281 out 486). Please note that more downregulated genes are detected when neuronal nuclei are analyzed suggesting that some of the differences may be

1113 masked by cell type heterogeneity when bulk tissue is analyzed. 205 genes are exclusively detected in 1114 the bulk tissue analysis. This might be explained by the fact that especially the cytoplasmatic and 1115 synaptic transcriptome is subjected to dynamic changes in post-transcriptional modifications such a 1116 RNA-methylation and the regulation by microRNAs, that may even originate from other cells in a 1117 paracine manner \{Epple, 2021\}. B-D. The view that both transcriptomes reflect relevant changes due 1118 to the loss of Setdlb is supported by GO analysis revealing similar pathways that are linked to 1119 neuronal plasticity, and the fact that within the TOP 30, 8 GO-terms are identical, amongst then for 1120 example "positive regulation of ERK1 and ERK2 cascade", "memory" or "positive regulation of 1121 axon extension". 
bioRxiv preprint doi: https://doi.org/10.1101/2021.08.02.454636; this version posted August 2, 2021. The copyright holder for this preprint (which was not certified by peer review) is the author/funder, who has granted bioRxiv a license to display the preprint in perpetuity. It is made available under aCC-BY-ND 4.0 International license.

1123 Expanded view Fig. 10: Comparison of the genes downregulated in Setdla heterozygous mutant

1124 and Setd1b cKO mice. Venn diagram showing genes downregulated in Setdla heterozygous mutant

1125 vs Setdl $b$ cKO mice. Please note that genes affected in the different mutant mice are very different.

1126 The data from Setdla heterozygous mutant mice stems from a recent publication by Mukai et al.,

11272019 (PMID:31606247). Care has to be taken since in that study cortical tissue from heterozygous 1128 mice constitutively lacking Setdla was analyzed, while our data stems from the hippocampus of 1129 conditional knockout mice.

1131 Expanded view Fig. 11: Volcano plots showing differential gene expression in the three KMT cKO 1132 mice (data from bulk RNA-sequencing results is compared here) together with the overlay of neuron1133 specific genes. In accordance with our previous observations, although the total number of 1134 downregulated genes in each KMT cKO are comparable, more neuron-specific genes are affected in 1135 Setd $1 b \mathrm{cKO}$, followed by $K m+2 a \mathrm{cKO}$ and $K m+2 b \mathrm{cKO}$.

1137 Expanded view Fig. 12: A. Profile plot representing, in wild type mice, the average H3K4me3 1138 distribution around TSS of all genes that display decreased H3K4me3 in Setd1b cKO, Kmt2a cKO or $1139 \quad K m t 2 b$ cKO neurons. B. Bar plots representing the number of genomic regions in distance to the TSS 1140 that show significantly decreased H3K4me3 in Kmt2a cKO, Kmt $2 b$ cKO and Setd $1 b$ cKO neurons 1141 binned into $0-2 \mathrm{~kb}$ and $0-5 \mathrm{~kb}$ upstream or downstream of the TSS. Note that more regions are 1142 detected in Setdlb cKO neurons when the region more distant to the TSS (0-5bk) is analyzed. C-E.

1143 Pie charts depicting the genomic distribution of regions with decreased H3K4me3 in Kmt2a cKO (C),

$1144 \quad \underline{K} m t 2 b \mathrm{cKO}(\mathrm{D})$ and Setdl $b \mathrm{cKO}(\mathrm{E})$ neurons.

1146 Expanded view Fig. 13: Functional categories affected in Kmt2a and Kmt2b cKO mice. A. Heat 1147 map showing functional GO category analysis for genes downregulated in Kmt2a cKO mice. 1148 Enrichment of the same categories is also shown for Kmt2b and Setdlb cKO mice. B. Heat map 1149 showing functional GO category analysis for genes downregulated in $K m t 2 b$ cKO mice. Enrichment 1150 of the same categories is also shown for Kmt2a and Setdlb cKO mice. Please note that the GO 1151 categories affected in Kmt2a or Kmt2b cKO mice differ substantially from those affected in Setdlb 1152 cKO mice. All analyses are based on comparable RNA-seq data generated from bulk hippocampal 1153 CA region.

1155 Expanded view Fig. 14: Comparison of H3K4me3 changes in Setd1b cKO, Kmt2a cKO, Kmt2b 1156 cKO and CK-p25 mice. Overlap of TSS regions $(+/-2 \mathrm{~kb})$ with decreased H3K4me3 in each of the 1157 three KMT cKO mice with those decreased in mouse model for Alzheimer's model (CK-p25 mice) 1158 (Gjoneska et al., 2015). The patter of overlapping regions (Setd1b > Kmt2a > Kmt2b) is in agreement 
with our suggested role of the $3 \mathrm{KMTs}$ in the regulation of neuronal genes important for memory

1160 function. A highly significant overlap was only seen in case of Setdlb cKO mice (580 out of 997

1161 regions; hypergeometric test: $p$-value $=0)$. The overlap between $K m t 2 a$ cKO and CK-p25 is much

1162 smaller (195 TSS regions) but still remains significant according to the hypergeometric test ( $p$-value $=$

1163 0.00000292). The overlap between $K m t 2 b$ cKO and CK-p25 is in turn negligible (85 TSS regions)

1164 and is not significant (hypergeometric test: $p$-value $=1$ ). It is important to note that we re-analyzed 1165 our ChIP-seq data from Kmt2a,Kmt2b and Setdlb cKO mice together with the data from the CK-p25 1166 mice and selected only genomic regions which showed H3K4me3 signal in all datasets to allow for a 1167 reliable comparison. Thus, the total numbers of H3K4me3 regions that differ between conditions are 1168 slightly different to our results reported for example in Fig. 4A. This is also due to the fact that 1169 Gjoneska et al. analyzed bulk hippocampal tissue, whereas our experiments are based on sorted 1170 hippocampal neurons from the CA region. Nevertheless, the fact that the overlap is still substantial 1171 with Setdlb cKO and lower or negligible in the other two KMT cKOs supports the view that Setdlb is 1172 particularly important for regulating genes important for synaptic plasticity and memory function.

1174 Expanded view Fig. 15. Comparative analysis of learning and single nucleus gene expression of

$1175 \underline{K m t 2 a, K m t 2 b}$ and Setd1b. A. Comparison of the escape latency in the 3 different KMT cKO mice 1176 during 10 days of training. Although we applied the same experimental setting, the experiments were 1177 performed at different time points ((Kerimoglu et al., 2013) (Kerimoglu et al., 2017), and this study). 1178 Thus, for comparison we normalized the data to the corresponding control group. In this plot an 1179 increase in the fold change of the normalized escape latency depicts the difference to the 1180 corresponding control group. Hence, a higher fold change oft he normalized escape latency indicates a 1181 greater difference to the corresponding control and thus more severe learning impairment. Setdlb 1182 cKO $(\mathrm{n}=14)$ vs $K m t 2 a \mathrm{cKO}(\mathrm{n}=13)$ : Repeated measures ANOVA, genotype effect: $\mathrm{F}(1,25)=$ 118316.83 , *** $p$-value $<0.001$. Setdlb cKO $(\mathrm{n}=14)$ vs $K m t 2 b \mathrm{cKO}(\mathrm{n}=22)$ : Repeated measures 1184 ANOVA, genotype effect: $\mathrm{F}(1,34)=70.66, * * * * p$-value $<0.0001$. B. UMAP plot showing the data 1185 from 15661 nuclei. Upper panel shows the different clusters and their corresponding numbers. The 1186 lower panel shows the same UMPA plot colored for different groups of cells that are further analyzed 1187 in (C) and (D). C. Violin plot showing the expression of the 6 KMTs as well as marker genes for the 1188 different hippocampal cell types according the UMAP shown in lower panel B. Note that Kmt2a and

$1189 \underline{K m t 2 c}$ are the highest expressed KMTs across cell types, while the other KMTs shown low to 1190 moderate expression. D. Violin plot showing the expression of the six KMTs and corresponding 1191 marker genes within the different cluster representing inhibitory and excitatory neurons. Note that 1192 there is no obvious difference of KMT expression between cell types. In agreement with the data 1193 shown in panel (C), Kmt2a and Kmt2c exhibit the highest expression levels. D. Bar charts showing 1194 the total number of reads/cell that are positive for the corresponding KMT. E. Left panel shows

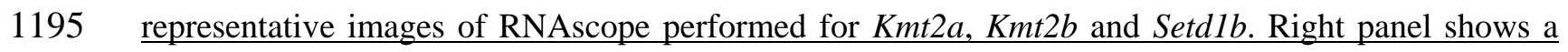



made available under aCC-BY-ND 4.0 International license.

1196 bar chart quantifying the dots/cell $(\mathrm{n}=1500$ cells from 2 mice $)$ indicative of the corresponding

1197 expression level. Kmt2a expression was significantly higher when compared to Kmt $2 b$ or Setdlb (***

$1198 \quad p$-value $<0,0001$, Student t-test).

1199

1200

1201 


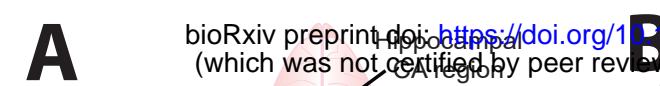

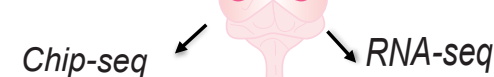

Fixation \& Nuclei

isolation by sucrose

gradient centrifugation

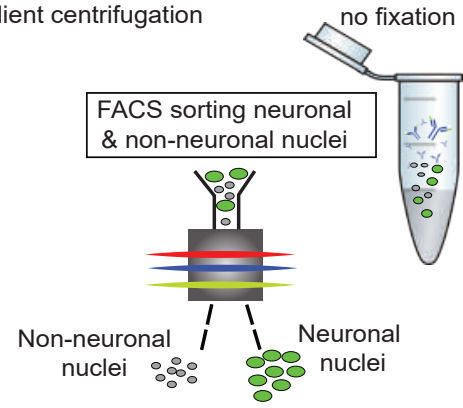

Chromatin/RNA isolation

for neuronal specific

ChIP-seq or RNA-seq
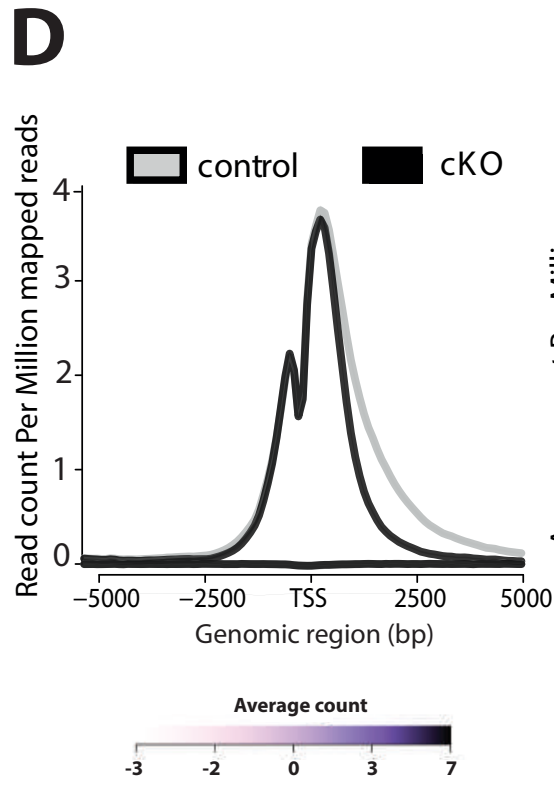

G
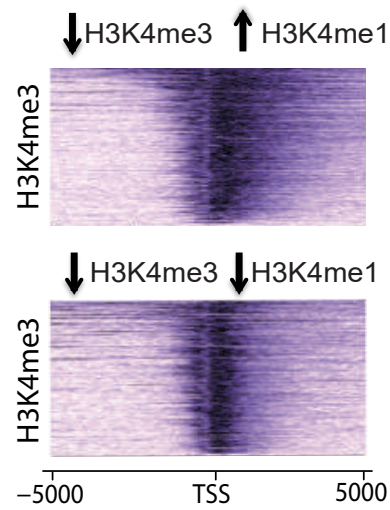
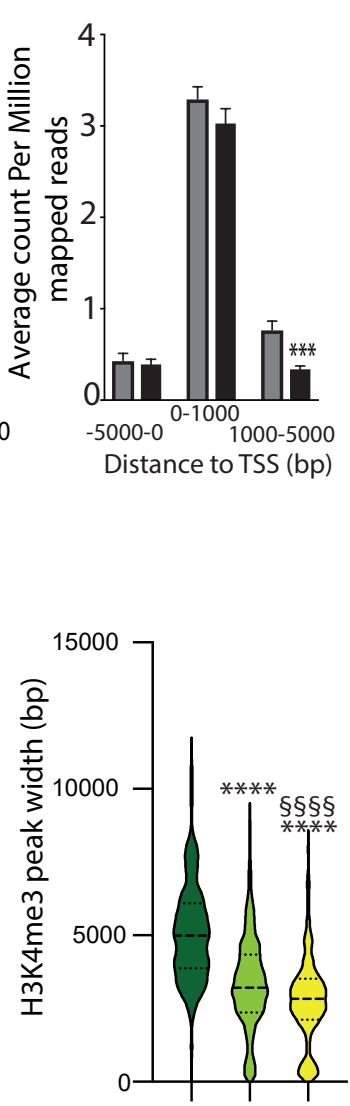

E
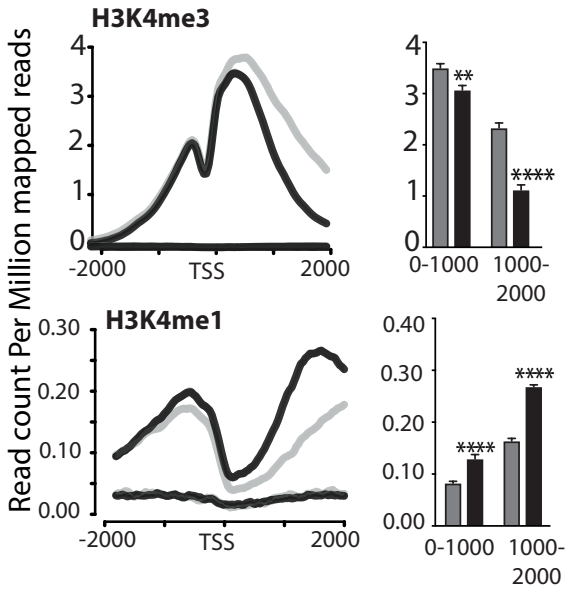

Genomic region/distance to TSS (BP)

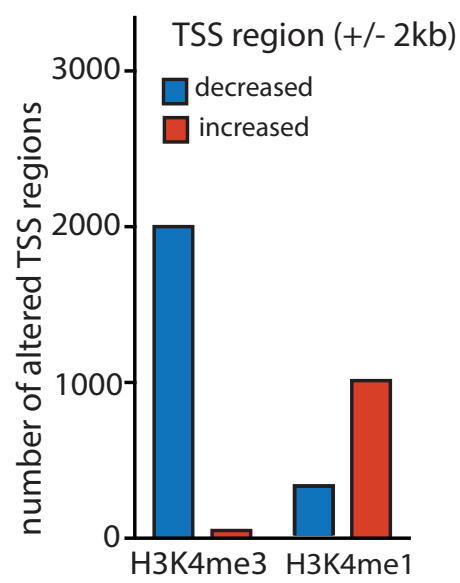

E

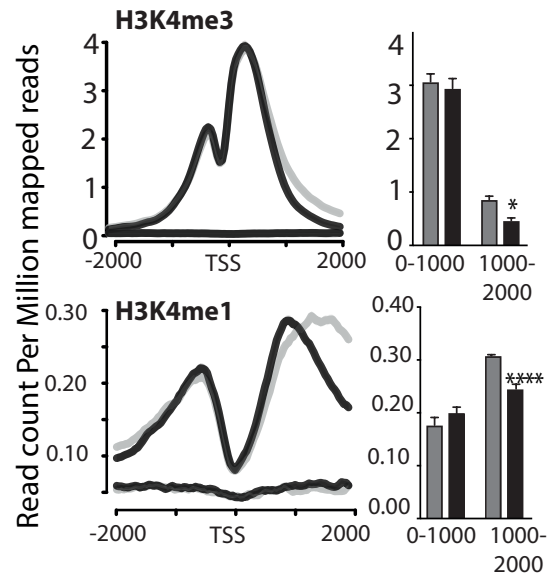

Genomic region/distance to TSS (BP)

H

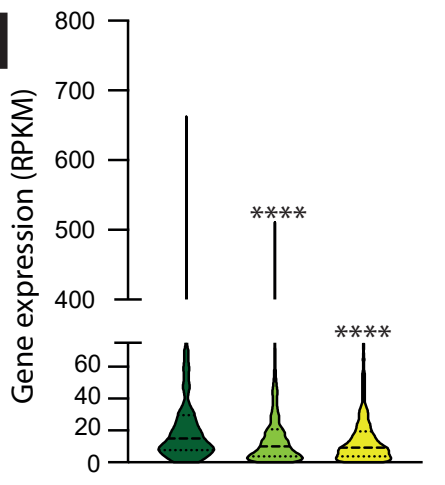

Genes with decreased

H3K4me3 \& increased H3K4me1

Genes with Decreased

H3K4me3 \& No Change H3K4me1

Genes with decreased

H3K4me3 \& decreased H3K4me1

-log(p-value)

6

$\checkmark$

N
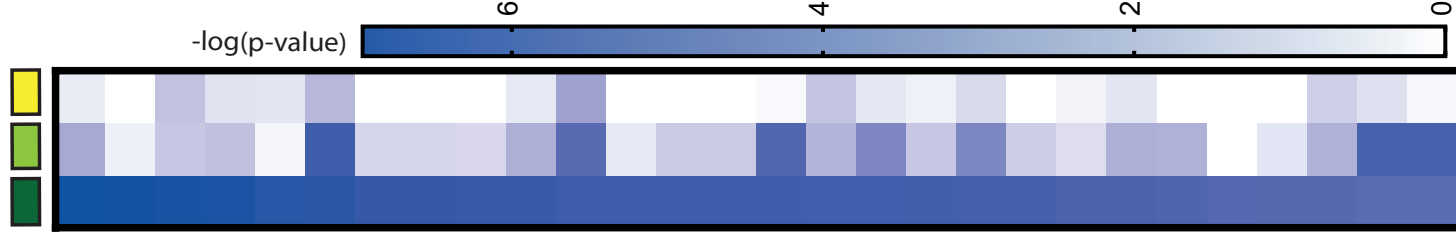

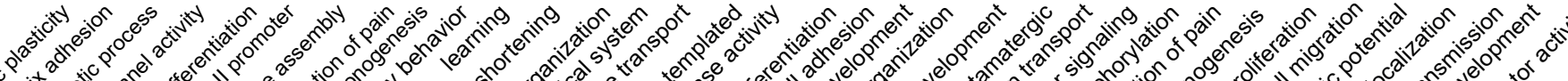

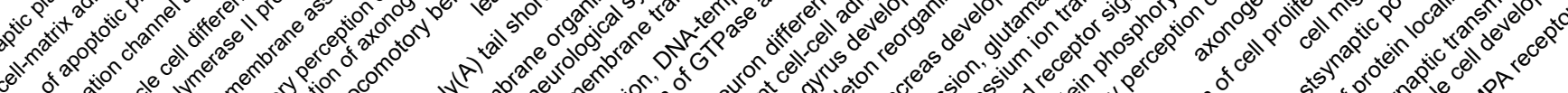
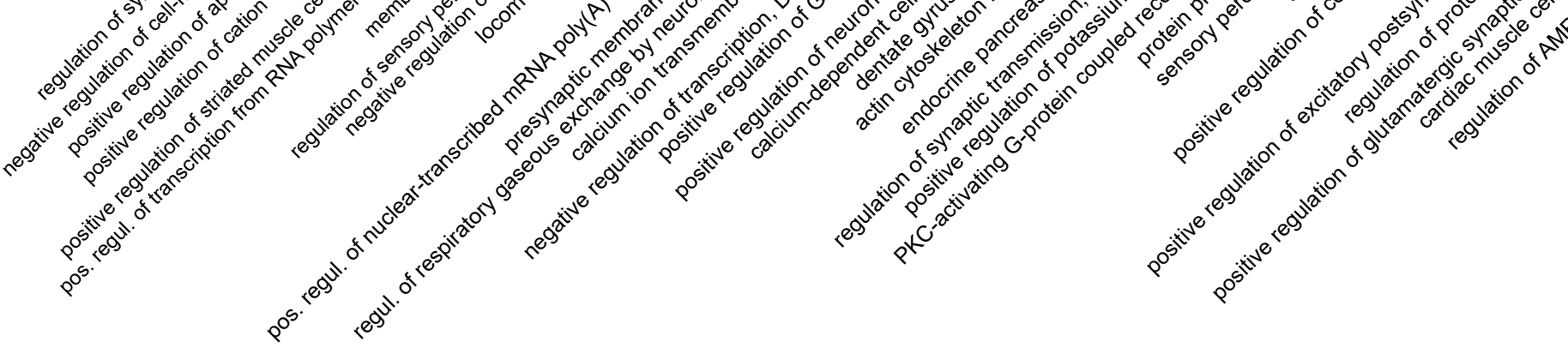
bioRxiv preprint doi: https://doi.org/10.1101/2021.08.0 54636; this version posted August 2, 2021. The copyright holder for this preprint

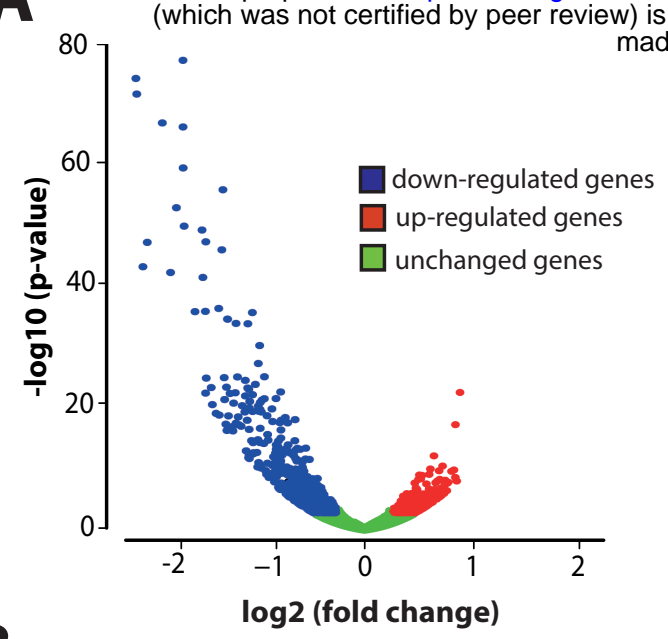

B
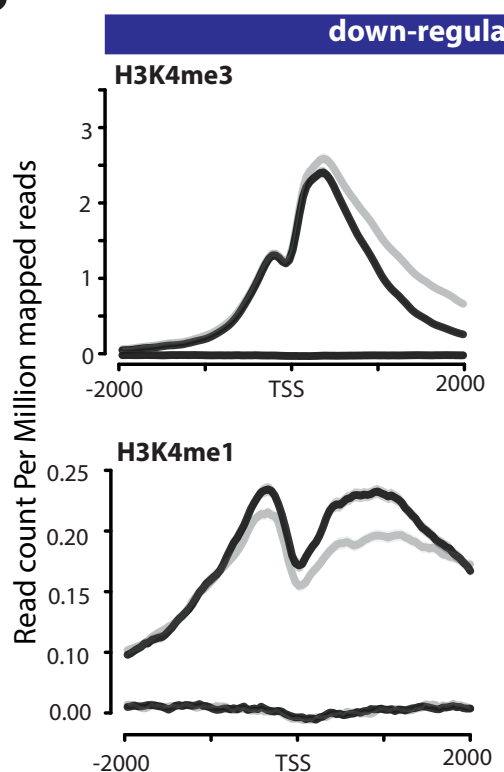

Genomic region/distance to TSS (BP)
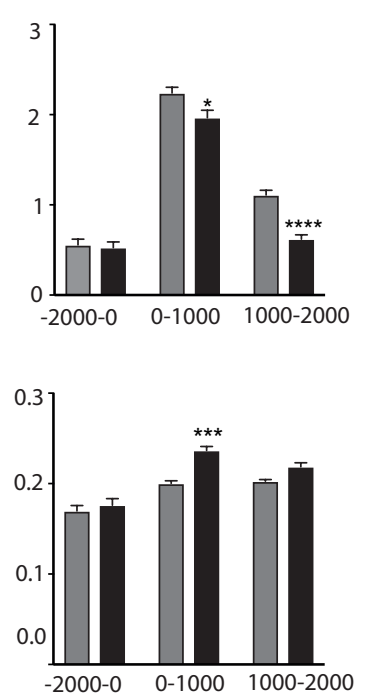

Genomic region/distance to TSS (BP)
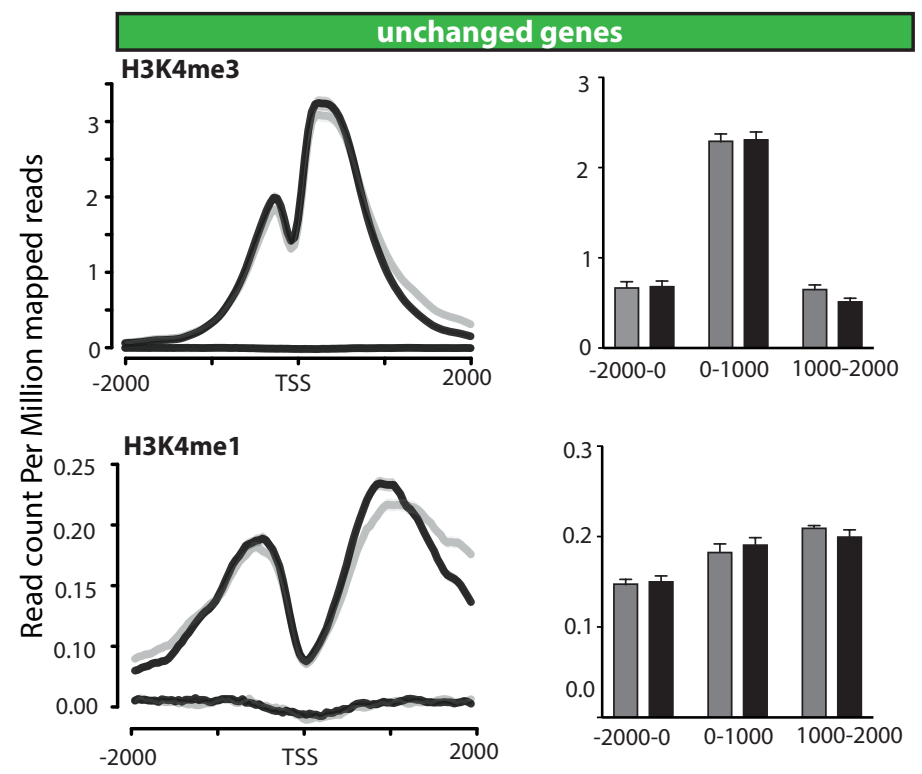

Genomic region/distance to TSS (BP)

control

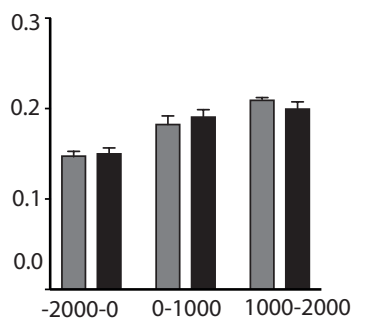

Genomic region/distance to TSS (BP)
E
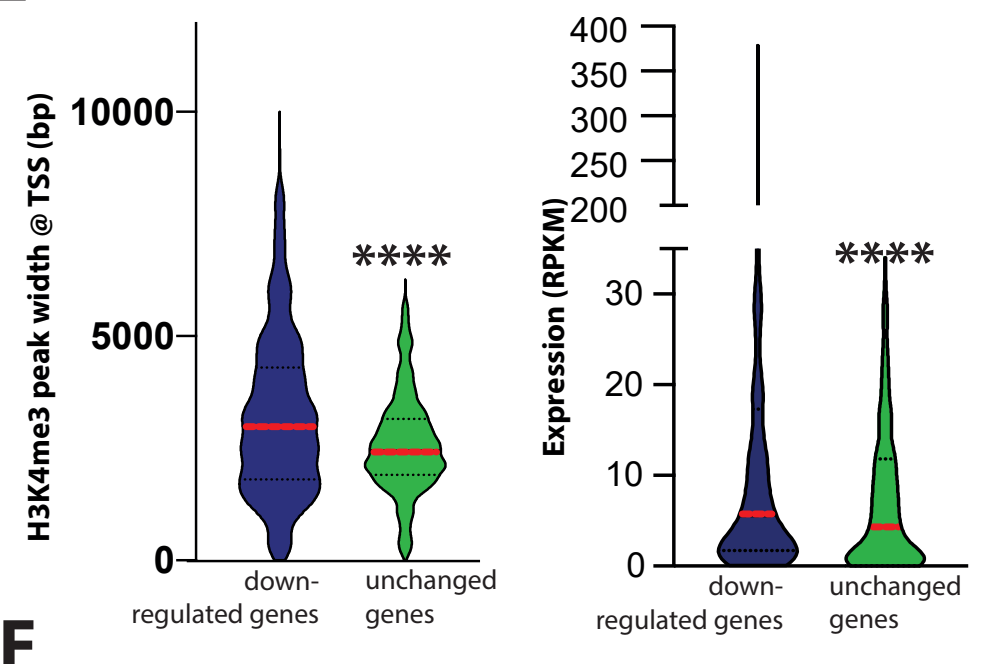

positive regulation of ERK1 and ERK2 cascade response to estradiol extracellular matrix organization positive regulation of axon extension serotonin receptor signaling pathway behavioral fear response energy reserve metabolic process cell adhesion regulation of phospholipid biosynthetic process positive regulation of MAP kinase activity arachidonic acid metabolic process extracellular matrix assembly innervation neuropeptide signaling pathway receptor internalization memory

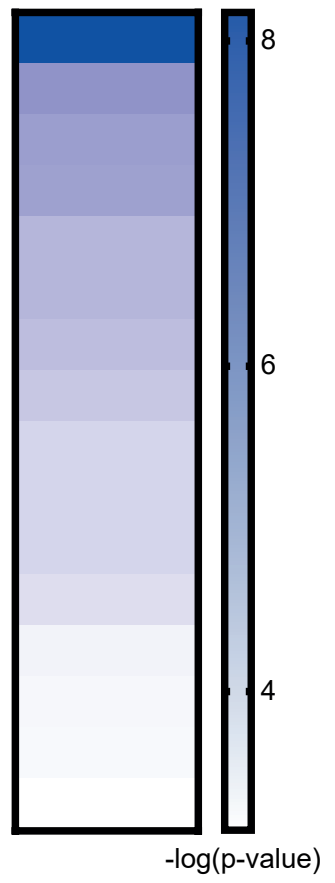



H3K4me3

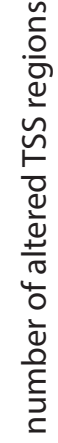

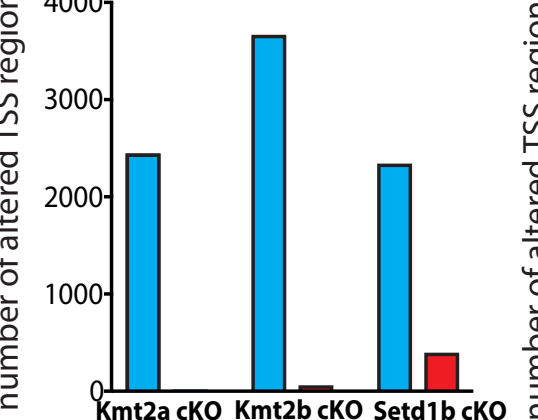

$\square$ decreased
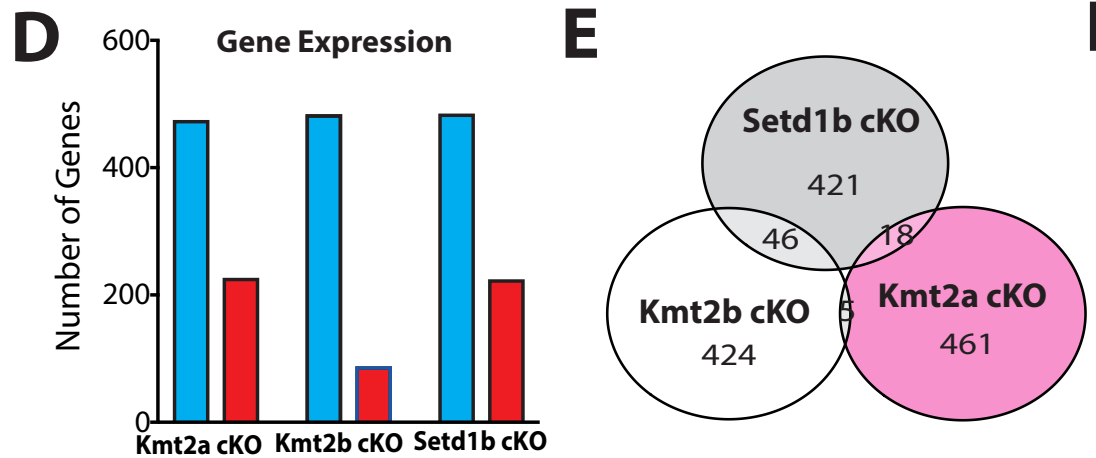

$\mathbf{E}$
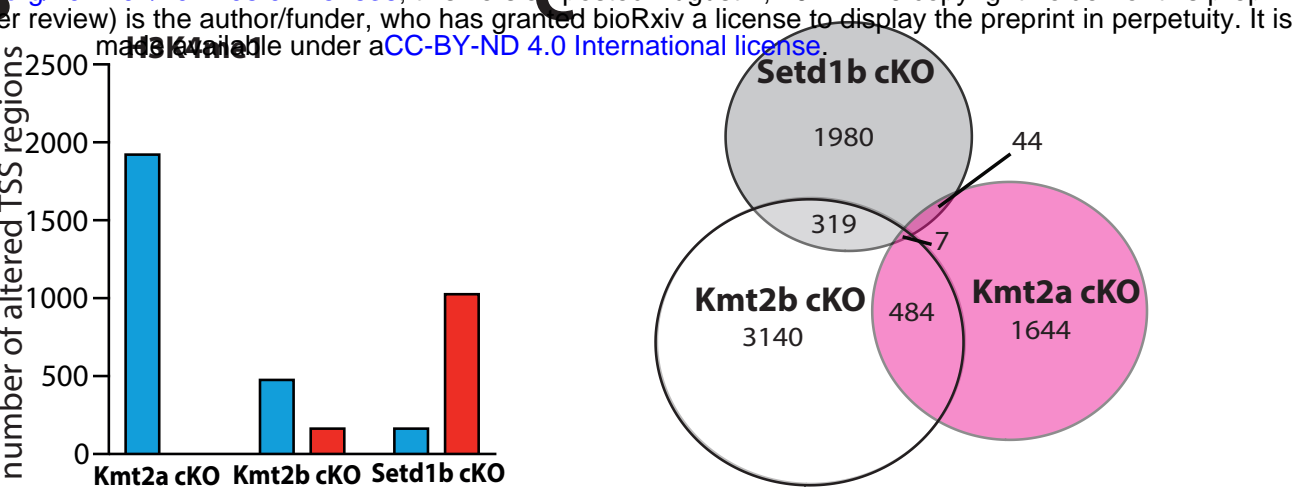

$\mathbf{F}$
G

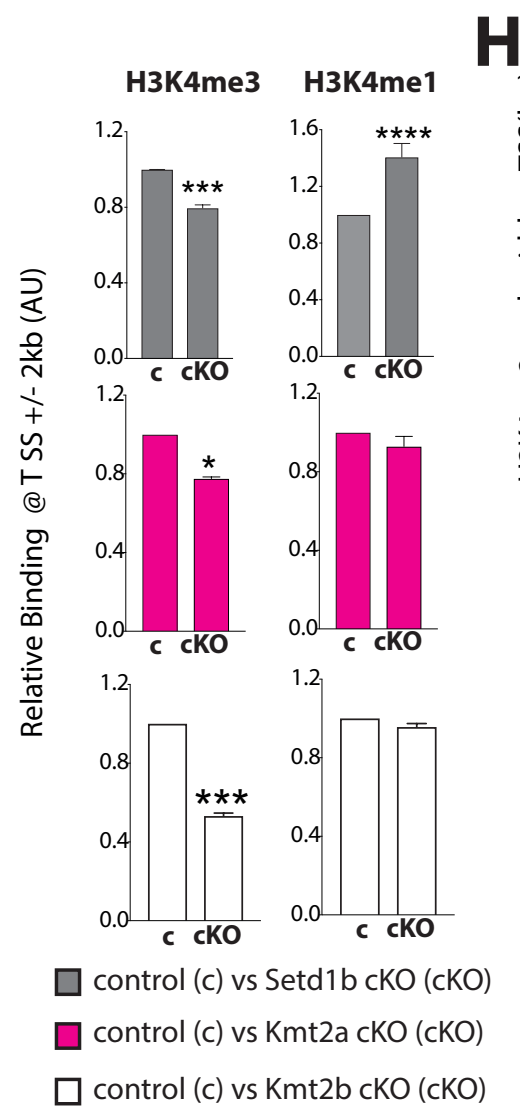

H

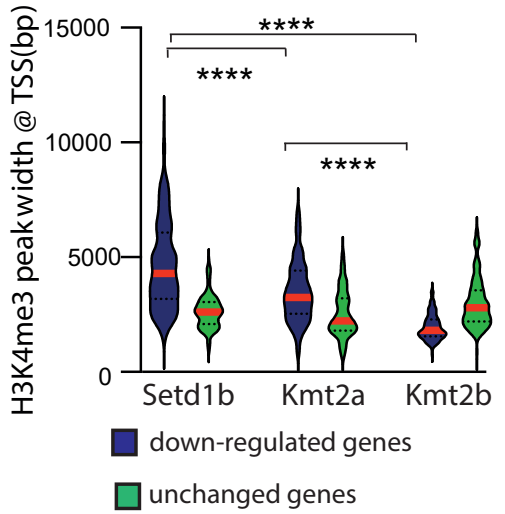

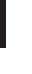

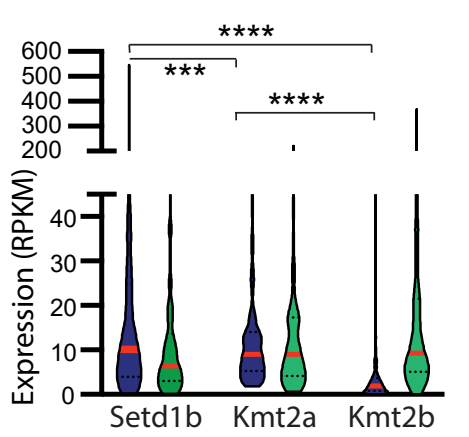

$\square$ down-regulated genes @ baseline

$\square$ unchanged genes@ baseline

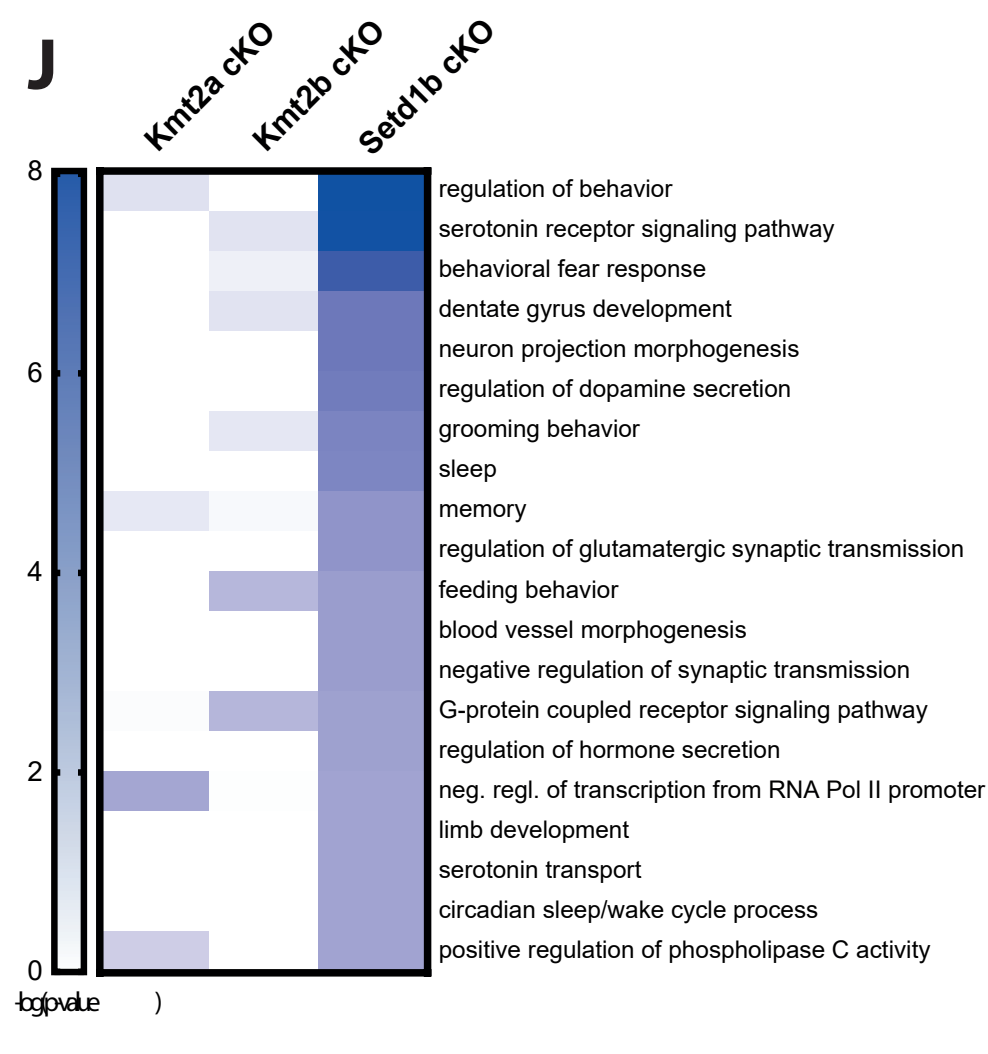

Figure 4 